\title{
PEGylation and antioxidant effects of a human glutathione peroxidase 1 mutant
}

\author{
Guang-Yuan Zhang ${ }^{1,}{ }^{*}$, Yan-Wei Wang ${ }^{1,{ }^{*}}$, Li-Ying Guo ${ }^{1}$, Liang-Ru Lin ${ }^{1}$, Shao-Peng Niu ${ }^{1}$, Chang-Hao \\ Xiong ${ }^{1}$, Jing-Yan $\mathrm{Wei}^{1,2}$ \\ ${ }^{1}$ College of Pharmaceutical Science, Jilin University, Changchun 130021, PR China \\ ${ }^{2}$ Key Laboratory for Molecular Enzymology and Engineering of the Ministry of Education, Jilin University, \\ Changchun 130000, PR China \\ *Equal contribution as co-first authors
}

Correspondence to: Jing-Yan Wei; email: jingyanweijluedu@163.com, https://orcid.org/0000-0002-5707-5260 Keywords: PEGylation, human glutathione peroxidase 1 mutant, antioxidant, cardiotoxicity, thermal stability

Received: September 27, 2021 Accepted: December 29, $2021 \quad$ Published: January 12, 2022

Copyright: (C) 2022 Zhang et al. This is an open access article distributed under the terms of the Creative Commons Attribution License (CC BY 3.0), which permits unrestricted use, distribution, and reproduction in any medium, provided the original author and source are credited.

\section{ABSTRACT}

Human glutathione peroxidase1 (hGPX1) is a good antioxidant and potential drug, but the limited availability and poor stability of hGPx1 have affected its development and application. To solve this problem, we prepared a hGPx1 mutant (GPX1M) with high activity in an Escherichia coli BL21(DE3)cys auxotrophic strain using a single protein production (SPP) system. In this study, the GPx1M was conjugated with methoxypolyethylene glycolsuccinimidyl succinate (SS-mPEG, $M_{w}=5 \mathrm{kDa}$ ) chains to enhance its stability. SS-mPEG-GPx1M and GPx1M exhibited similar enzymatic activity and stability toward $\mathrm{pH}$ and temperature change, and in a few cases, SS-mPEG-GPX1M was discovered to widen the range of $\mathrm{pH}$ stability and increase the temperature stability. Lys 38 was confirmed as PEGylated site by liquid-mass spectrometry. H9c2 cardiomyoblast cells and SpragueDawley (SD) rats were used to evaluate the effects of GPx1M and SS-mPEG-GPx1M on preventing or alleviating adriamycin (ADR)-mediated cardiotoxicity, respectively. The results indicated that GPx1M and SS-mPEG-GPx1M had good antioxidant effects in vitro and in vivo, and the effect of SS-mPEG-GPX1M is more prominent than GPx1M in vivo. Thus, PEGylation might be a promising method for the application of GPx1M as an important antioxidant and potential drug.

\section{INTRODUCTION}

Natural human glutathione peroxidase 1 (hGPx1) is an important antioxidant enzyme that can protect the body from oxidative damage by catalyzing the reduction of hydroperoxides using glutathione (GSH) as a reductant [1]. However, the use of hGPx1 is affected by its limited sources and poor stability [2,3]. To solve this problem, we prepared a high yield and catalytic activity selenium-dependent glutathione peroxidase 1 mutant (GPx1M) by mutating cysteine (C 78, C 115, and C 156) in hGPx1 to serine in an Escherichia coli BL21(DE3)cys auxotrophic strain using a single protein production (SPP) system [4]. The GPx1M exhibited high activity, which is 5-fold more than natural bovine liver GPx, and its stability was improved compared with the that of hGPx1. As with many other therapeutic peptides and proteins, GPx1 has a low stability and short plasma half-life [5]. These shortcomings limit the clinical application of GPx1 and its mutant protein.

PEGylation, an effective and well-known strategy to prevent the shortcomings of peptides and proteins, has led to 12 marketed drugs [6]. Such as PEGylated asparaginase $\left(\right.$ Oncaspar $\left.^{\circledR}\right)$ [7], PEGylated interferon $\alpha-2 b$ (PEG-Intron ${ }^{\circledR}$ ) [8], and PEGylated adenosine deaminase (Adagen ${ }^{\circledR}$ ) [9]. The modification of proteins by the covalent conjugation of polyethylene glycol (PEG) 
shows great potential for enhancing enzyme stability [10], preventing effects due to temperature, $\mathrm{pH}$, and proteolytic digestion [11], and improving pharmaceutical properties $[12,13]$. Proteins conjugated with PEG not only show reduced immunogenicity and renal clearance [14] but also exhibit improved half-time and stability in the blood [15] by preventing hydrolysis with proteolytic enzymes [16]. The circulation of PEGylated proteins can avoid the necessity of multiple injections to patients. This prompted us to consider whether PEGylation of GPx1M could improve its stability but not affect its activity as an antioxidant enzyme. To date, modification of GPx1M by PEG has never been reported, and the antioxidant effect of GPx1M and the modified product at the cellular level has not been reported in literatures.

Adriamycin (ADR) is a quinone-containing drug for treating malignancy [17] that is limited in clinical use due to its severe cardiotoxicity [18]. The toxicity of ADR is attributed to the generation of large amounts of reactive oxygen species (ROS) and lipid peroxidation in cardiomyocytes [19]. Lipid peroxidation is initiated by free radicals, causing the oxidative destruction of polyunsaturated fatty acids in cellular membranes. This destruction leads to the generation of malondialdehyde (MDA) [20]. Lactate dehydrogenase (LDH) is an intracellular enzyme for indicating cell membrane damage [21], which can be generated by oxidative stress. Therefore, ADR was selected as a model drug to test the antioxidant capacity of GPx1M and its PEGylation.

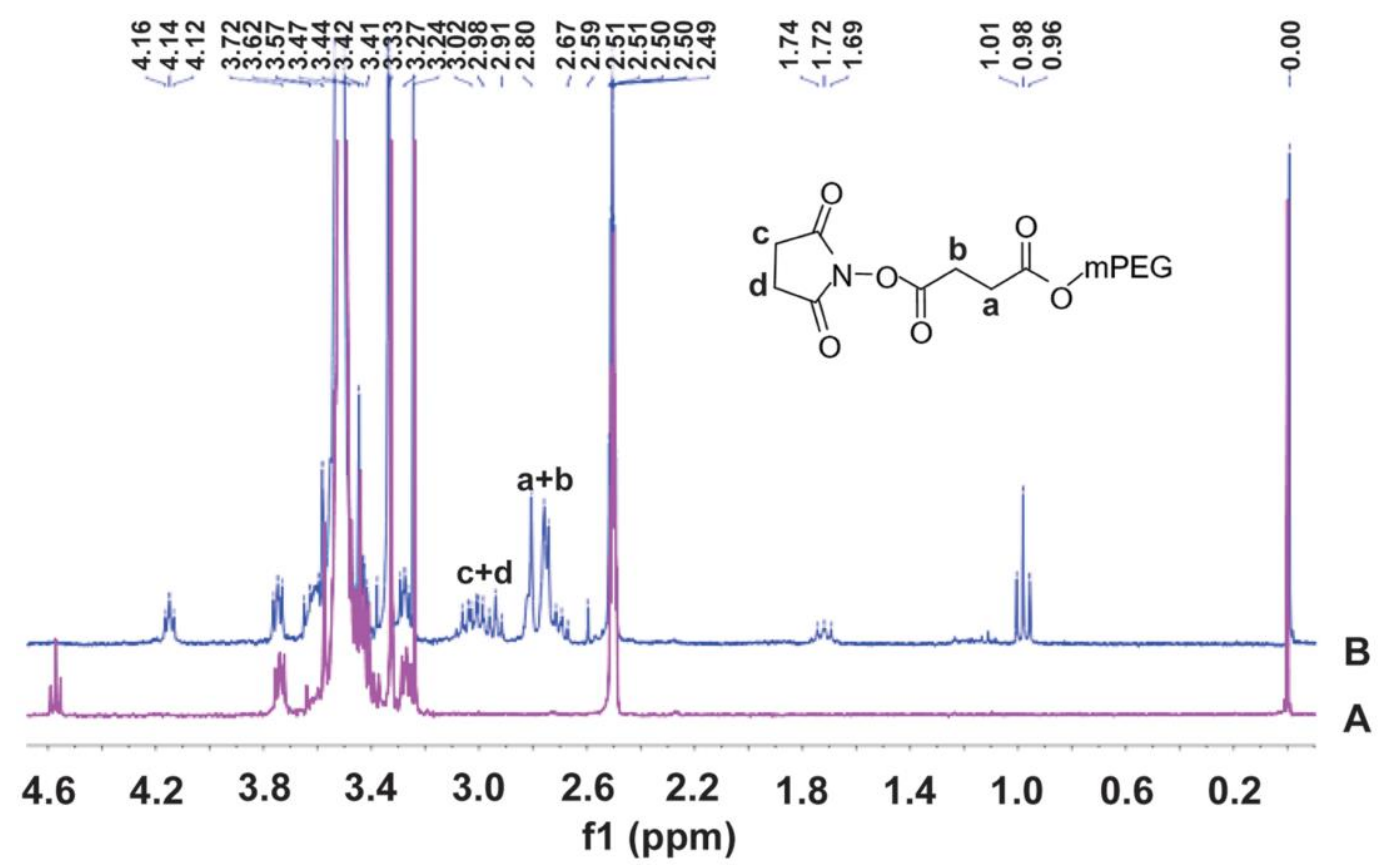

In the present study, the GPx1M was modified by methoxypolyethylene glycol succinimidyl succinate $\left(\mathrm{SS}-\mathrm{mPEG}, M_{\mathrm{w}}=5 \mathrm{kDa}\right)$. The synthesis route of SSmPEG and SS-mPEG conjugated GPx1M (SS-mPEGGPx1M) was established. SS-mPEG was confirmed by ${ }^{1} \mathrm{H}$ nuclear magnetic resonance ( $\left.{ }^{1} \mathrm{H}-\mathrm{NMR}\right)$ spectrometry. SS-mPEG-GPx1M was characterized in terms of sodium dodecyl sulfate-polyacrylamide gel electrophoresis (SDS-PAGE), iodine staining, and matrix-assisted laser desorption ionization time of flight mass spectrometry (MALDI-TOF-MS). PEGylation site was confirmed by the liquid chromatograph-electrospray ionization-mass spectrometer (LC-ESI-MS). The enzyme stability was evaluated at different temperatures and $\mathrm{pH}$ values. Cell viability, lipid peroxidation, cell membrane damage, cellular apoptosis and cellular ROS content were also investigated to reveal the protective effects of SS-mPEGGPx1M and GPx1M on H9c2 cells. Animal experiments were performed to evaluate the antioxidant effects and pharmacokinetic of SS-mPEG-GPx1M in vivo. This study developed a PEGylated GPx1M with SS-mPEG for the first time and demonstrated that PEGylated GPx1M had greater potential antioxidant properties than that of GPx1M.

\section{RESULTS}

\section{Characterization of SS-mPEG}

The ${ }^{1} \mathrm{H}-\mathrm{NMR}$ spectra of $\mathrm{mPEG}$ and SS-mPEG were shown in Figure 1. Compared to the standard spectrum of $\mathrm{mPEG}$, several new peaks showing a characteristic

\section{A}

Figure 1. ${ }^{1} \mathrm{H}$ Nuclear magnetic resonance $\left({ }^{1} \mathrm{H}-\mathrm{NMR}\right)$ spectra of methoxy polyethylene glycol (A) and methoxy polyethylene glycolsuccinimidyl succinate $(\mathbf{B})$ in $\mathrm{DMSO}_{\mathrm{d} 6}$. 
absorption at $\delta_{2.67-3.24} \mathrm{ppm}$ were observed for SSmPEG. The $\delta_{1.69}, \delta_{1.72}, \delta_{1.74}$ and $\delta_{1.76}$ ppm peaks correspond to diethylether methylene protons. The $\delta_{0.96}$, $\delta_{0.98}$, and $\delta_{1.01} \mathrm{ppm}$ peaks correspond to diethyl methylene protons. Methylene proton signals from NHS were observed at $\delta_{2.91-3.24} \mathrm{ppm}$. The $\delta_{2.67-2.80} \mathrm{ppm}$ peaks correspond to SA methylene proton signals.

\section{Preparation and characterization of SS-mPEG- GPx1M}

The predicted molecular weights from the SDS-PAGE results indicated that the GPx1M conjugate contains a single PEG molecule (Figure 2A). Analysis of Figure $2 \mathrm{~A}$ by Image $\mathrm{J}$ showed that the ratio of SS-mPEGGPx1M to unmodified GPx1M was 1:1.83, and the modification rate of SS-mPEG-GPx1M was $35.33 \%$. The purification result of SS-mPEG-GPx1M was observed by SDS-PAGE analysis in Figure 2B-2C.

To analyze the molecular mass distribution of GPx1M with SS-mPEG, MALDI-TOF-MS was applied to confirm the SDS-PAGE results (Figure 2D). In the MALDI-TOF-MS result (a), $23805.3488 \mathrm{~m} / \mathrm{z}$ was GPx1M, and $28870.8557 \mathrm{~m} / \mathrm{z}$ was SS-mPEG-GPx1M. The result showed that GPx1M was successfully PEGylated with SS-mPEG. In the MALDI-TOF-MS result (b), $28877.9531 \mathrm{~m} / \mathrm{z}$ was the purified SS-mPEG-
GPx1M, and there was only one peak in the MS, indicating that the purified product has been obtained with high purity.

The temperature profiles of GPx1M and SS-mPEGGPx1M were shown in Figure 3A. The results revealed that both GPx1M and SS-mPEG-GPx1M presented a similar optimum temperature at $37^{\circ} \mathrm{C}$. SS-mPEGGPx1M exhibited a slight improvement in its thermal stability between $50-55^{\circ} \mathrm{C}$. GPx $1 \mathrm{M}$ exhibited $51.44 \%$ enzyme activity at $55^{\circ} \mathrm{C}$, whereas SS-mPEG-GPx1M retained $59.04 \%$ activity under the same conditions. The $\mathrm{pH}$ profiles for GPx1M and SS-mPEG-GPx1M presented an optimal activity peak at $\mathrm{pH} 9.0$ (Figure $3 \mathrm{~B})$. The enzyme activity of SS-mPEG-GPx1M was higher than free GPx1M over the studied $\mathrm{pH}$ values. The results indicated that the PEGylated strategy offered a method to protect against enzyme inactivation and improve the $\mathrm{pH}$ and thermal stability of GPx1M.

The effects of storage temperatures on SS-mPEG-GPx1M and GPx1M were determined. SS-mPEG-GPx1M and GPx1M had similar enzyme activity behaviors under the different temperature conditions, with a gradual decrease in activity during the storage period. However, there were statistically significant changes in the relative activity over the storage periods for SS-mPEG-GPx1M and GPx1M at different temperatures. The results showed
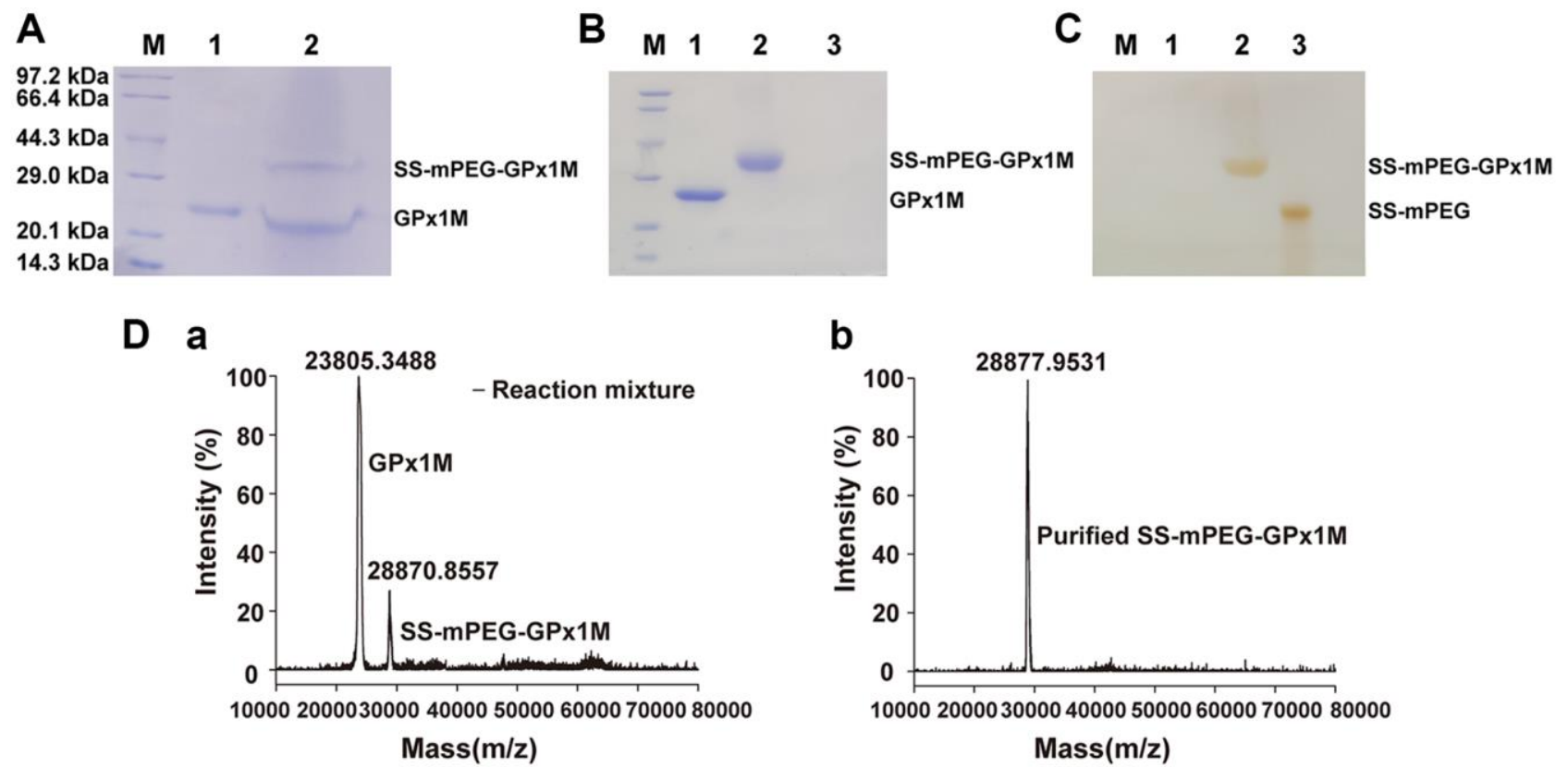

Figure 2. Characterization of SS-mPEG-GPx1M. (A) SS-mPEG-GPx1M form at mass ratio 1:50 stained with Coomassie Blue R-250. M, molecular weight standards. Lane 1, GPx1M. Lane 2, the reaction mixture with a molar ratio of 1:50 between GPx1M and SS-mPEG, including unmodified GPx1M and SS-mPEG-GPx1M. SDS-PAGE analysis of purified SS-mPEG-GPx1M with Coomassie Blue R-250 (B) and lodine stain (C). Abbreviation: M: molecular weight standards. Lane 1, GPx1M. Lane 2, purified SS-mPEG-GPx1M. Lane 3, SS-mPEG. (D) MALDI-TOF-MS of reaction mixture and purified SS-MPEG-GPx1M. (a) The MS image of reaction mixture. The reaction mixture mainly included unmodified GPx1M (23805.3488 m/z) and PEGylated product (SS-mPEG-GPx1M, $28870.8557 \mathrm{~m} / \mathrm{z}$ ). (b) The MS image of purified SS-mPEG-GPx1M. 
that the relative activity of SS-mPEG-GPx1M was superior to that of GPx $1 \mathrm{M}$ at $4^{\circ} \mathrm{C}$ and $-20^{\circ} \mathrm{C}$. After exposure for 150 days at $4^{\circ} \mathrm{C}$, GPx1M and SS-mPEGGPx1M retained $46.32 \%$ and $55.21 \%$ activity, respectively (Figure 3C). SS-mPEG-GPx1M showed $77.39 \%$ enzyme activity after 90 days at $-20^{\circ} \mathrm{C}$, whereas
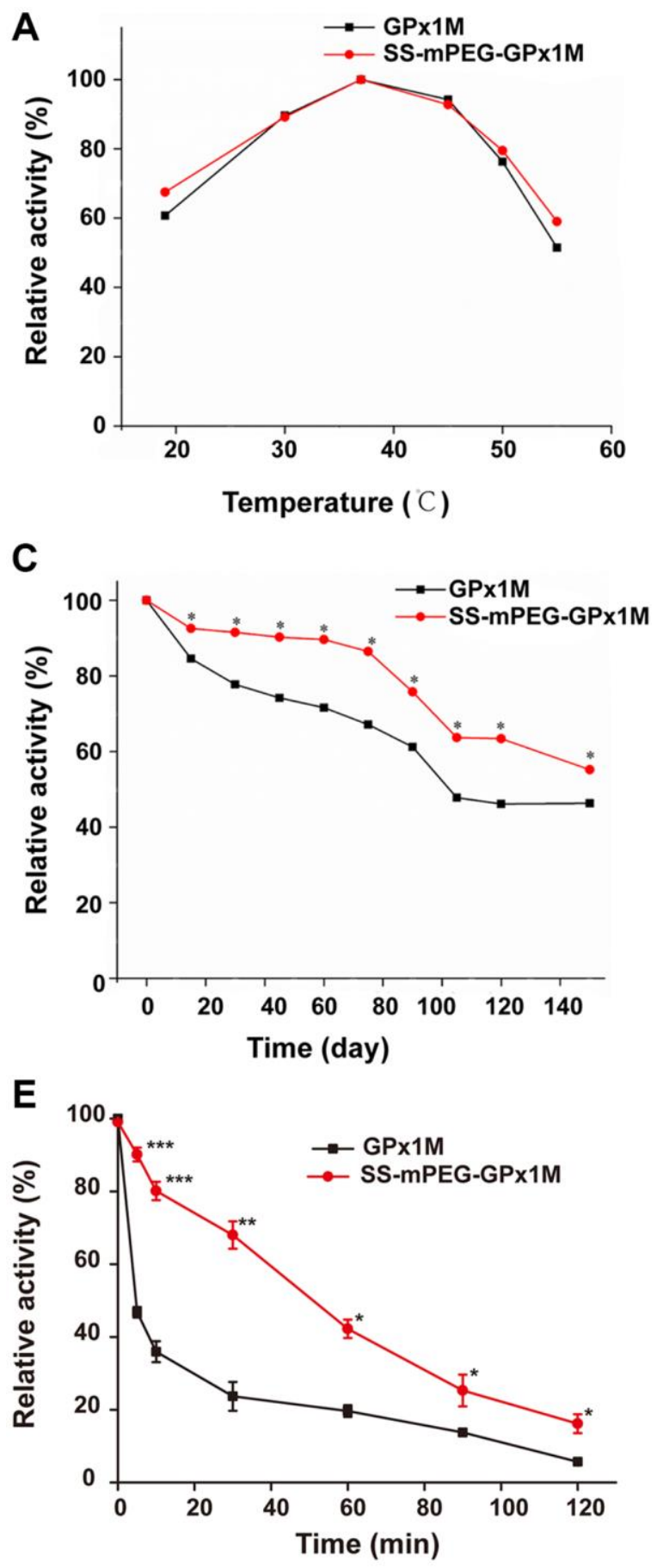

GPx1M retained $60.42 \%$ (Figure 3D). The above results demonstrated that PEGylation is an effective method to improve the long-term stability of GPx1M.

The results of the resistance of the modified product to protease could be observed in Figure 3E. The results
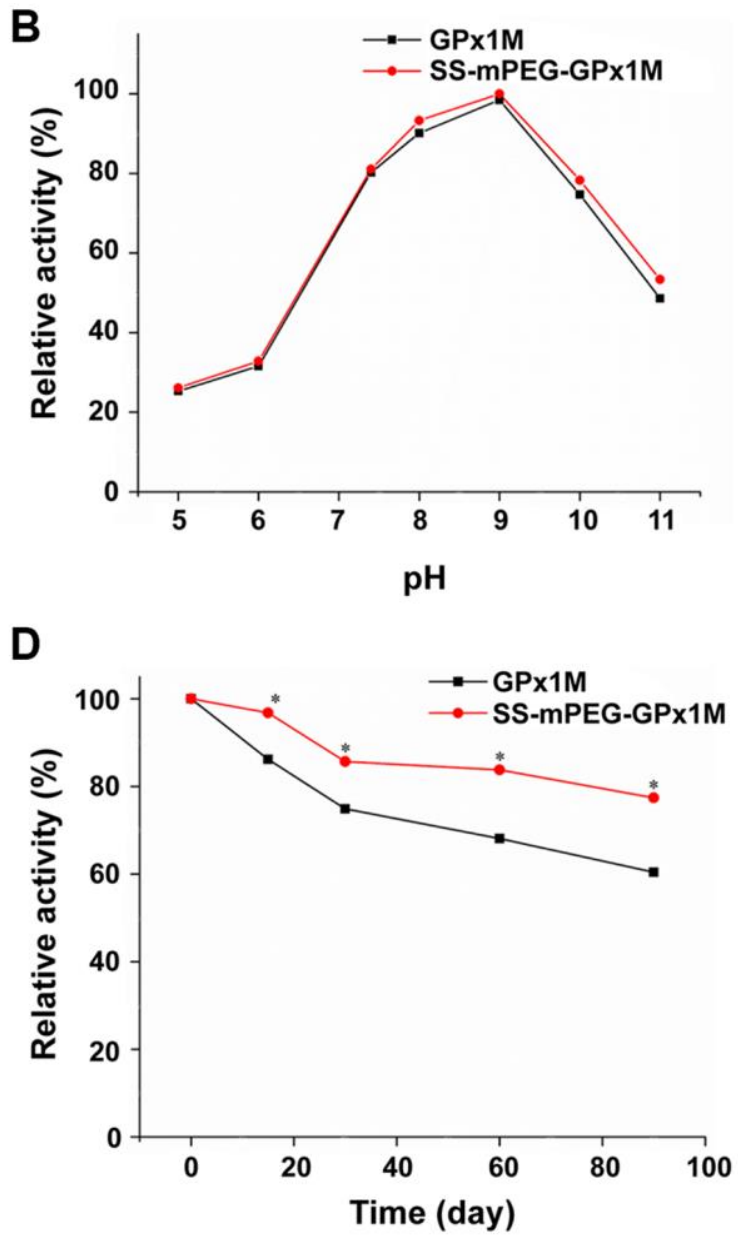

Figure 3. Determination of relative enzyme activity of SS-mPEG-GPx1M. Temperature (A) and pH (B) profiles of GPx1M and SSmPEG-GPx1M. (C) GPx1M and SS-mPEG-GPx1M were incubated in $50 \mathrm{mM}$ PBS at $4^{\circ} \mathrm{C}$ for a period ranging from 1 to 150 days. (D) GPx1M and SS-mPEG-GPx1M were incubated in $50 \mathrm{mM}$ PBS at $-20^{\circ} \mathrm{C}$ for a period ranging from 1 to 90 days. (E) The resistance of SS-mPEG-GPx1M to protease hydrolysis. All values were converted to a relative value, and the highest enzyme activity was set as $100 \%$. ${ }^{*} p<0.05,{ }^{* *} p<0.01$, and ${ }^{* * *} p<0.001$ vs. GPx1M. 
showed that the sensitivity of SS-mPEG-GPx1M to protease was significantly lower than that of GPx1M, indicating that PEGylation could increase the resistance of GPx1M to protease hydrolysis.

\section{PEGylation site}

All digestive products of SS-mPEG-GPx1M treated with trypsin were compared with digestions of GPx1M, and the peptide sequences LAAAAAAAQSVYAFSA RPLAGGEPVSLGSLRGK and VLLIENVASLCGTT VRDYTQMNELQR with missed cleavage site were only detected from the digestions of GPx1M (Figure 4A-4B). The application guide of MaxQuant software pointed out that the number of missing cleavage sites was allowed to be 1 or 2 , and the phenomenon of missing cleavage caused by trypsin was common in protein identification. The researchers used a data set composed of multiple proteins to prove that when lysine and arginine were adjacent to each other or were close, missing cleavage would occur. Meanwhile, when lysine and arginine were adjacent to aspartic acid, glutamic acid, or proline, the missing cleavage would also occur $[22,23]$. Moreover, in this study, the length of the two peptides did not exceed 33 amino acids, and both were within the range of mass spectrometry identification, so this result was normal and credible. The more information of the peptide sequences of LAAAAAAA QSVYAFSARPLAGGEPVSLGSLRGK was provided by ESI-MS (Figure 4C). The spatial structure of GPx1M with possible binding sites for PEGylated
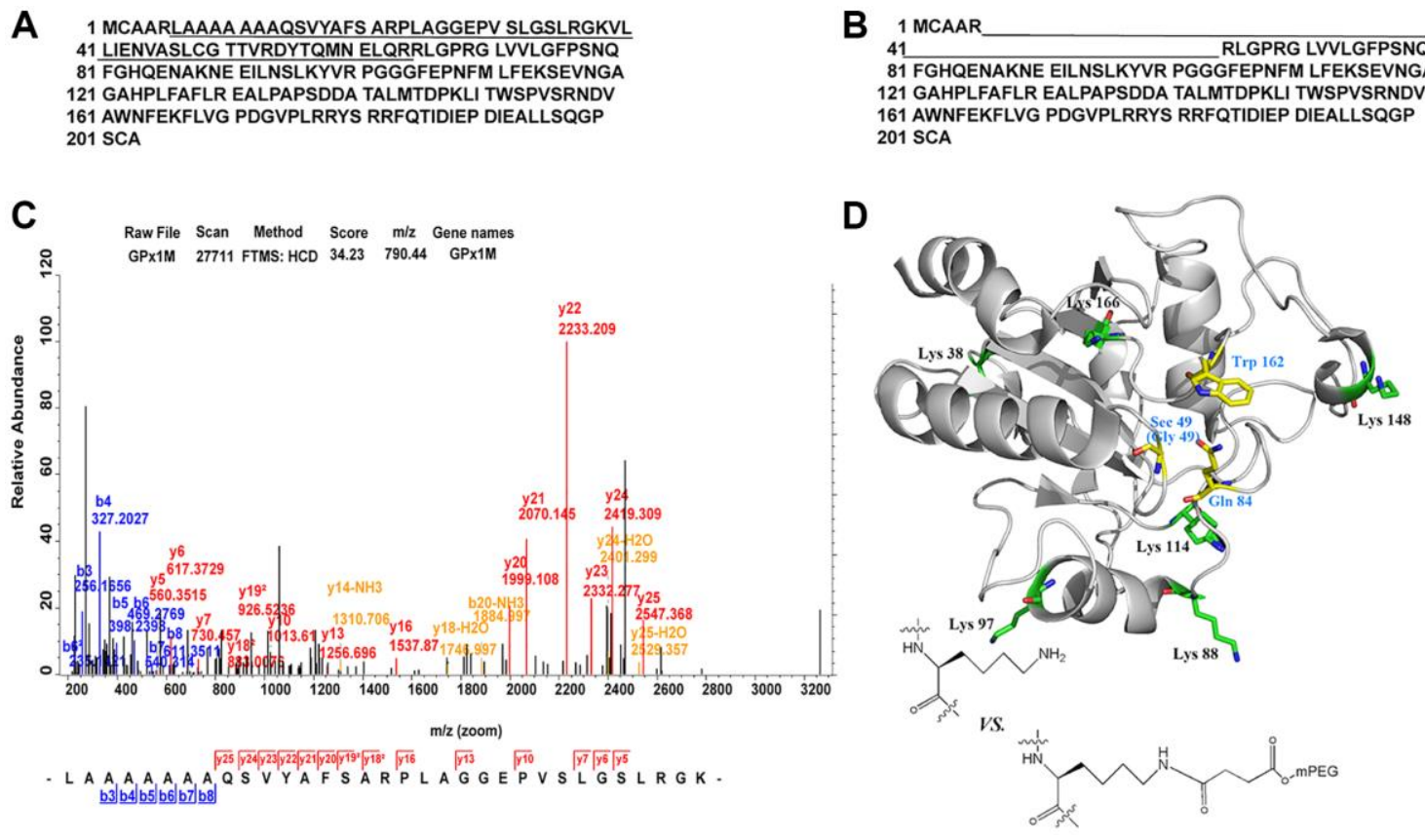

Figure 4. Identification of PEGylation site and spatial structure of GPx1M. (A) The peptide sequences derived from GPx1M digestions with trypsin. (B) The peptide sequences derived from SS-mPEG-GPx1M digestions with trypsin. (C) The ESI-MS analysis of peptides from digested GPx1M. (D) The structure of GPx1M with side chains shown as sticks. 
Table 1. Pharmacokinetic parameters of SS-mPEG-GPx1M in SD rats.

\begin{tabular}{lcccc}
\hline Sample & $\begin{array}{c}\boldsymbol{t}_{\mathbf{1} / \mathbf{2}^{\mathbf{a}}} \\
(\mathbf{h})\end{array}$ & $\begin{array}{c}\boldsymbol{C}_{\mathbf{m a x}}{ }^{\mathbf{b}} \\
(\mathbf{m g} / \mathbf{L})\end{array}$ & $\begin{array}{c}\boldsymbol{A} \boldsymbol{U} \boldsymbol{C}_{\mathbf{0}-\mathbf{1 2 0 ~}} \mathbf{h}^{\mathbf{c}} \\
(\mathbf{m g} / \mathbf{L} / \mathbf{h})\end{array}$ & $\begin{array}{c}\boldsymbol{C l / F ^ { \mathbf { d } }} \\
(\mathbf{m L} / \mathbf{h} / \mathbf{k g})\end{array}$ \\
\hline GPx1M & $14.73 \pm 1.72$ & $0.48 \pm 0.06$ & $7.95 \pm 0.72$ & $12.26 \pm 1.11$ \\
SS-mPEG-GPx1M & $24.04 \pm 0.39^{* *}$ & $0.51 \pm 0.04$ & $12.58 \pm 0.50^{* * *}$ & $7.84 \pm 0.34^{* * *}$ \\
\hline
\end{tabular}

${ }^{a}$ The blood circulation half-life. ${ }^{\mathrm{b}}$ The maximum blood concentration. ${ }^{\mathrm{C}}$ The area under the curve. ${ }^{\mathrm{d}}$ The clearance rate. ${ }^{* *} p<0.01$ vs. GPx1M.

$\mathrm{H} 9 \mathrm{c} 2$ cell cytotoxicity to obtain an optimal concentration of GPx1M and SS-mPEG-GPx1M which is both innocuous to cells and effective for alleviating ADR-induced cytotoxicity. The different concentrations of GPx1M and SS-mPEG-GPx1M (0.01-0.1 U/mL) were not cytotoxic toward H9c2 cells (Figure 6A). $\mathrm{H} 9 \mathrm{c} 2$ cell viability exhibited a slightly decrease at the $0.2-0.4 \mathrm{U} / \mathrm{mL}$ concentrations. However, ADR-induced cytotoxicity was dose-dependent. The viability of H9c2 cells treated with $2.5 \mu \mathrm{M}$ ADR was $56.88 \pm 5.27 \%$ (Figure 6B). This drug concentration was set as the model concentration for further investigation.

The results of pre-/cotreatment of GPx1M and SSmPEG-GPx1M on ADR-induced injury in H9c2 cells indicated that both pre-/coincubation of GPx1M and SS-mPEG-GPx1M notably decreased cytotoxicity and increased cell viability (Figure 6C-6D). Moreover, SSmPEG-GPx1M exhibited slightly enhanced protective effects than GPx1M on H9c2 cells. The result revealed that pre-/cotreatment with $0.08 \mathrm{U} / \mathrm{mL}$ of GPx1M $(84.06$ $\pm 3.01 \% / 76.19 \pm 1.17 \%)$ and SS-mPEG-GPx1M (86.65 $\pm 1.87 \% / 79.82 \pm 0.60 \%$ ) could alleviate ADR-induced damage and improve $\mathrm{H} 9 \mathrm{c} 2$ cell viability. Based on the above results, we selected $0.08 \mathrm{U} / \mathrm{mL}$ GPx1M and SSmPEG-GPx1M for further study.

The reduction in cell viability might be attributed to ADR-induced apoptosis in H9c2 cells. Figure 7 showed the morphological changes of apoptotic cells stained with
Hoechst 33258, exhibiting nuclei condensation and fragment staining. Hoechst 33258 staining revealed that exposure to ADR reduced the cell viability, and apoptotic cells appeared to be white in color. Pre-/coincubation with GPx1M and SS-mPEG-GPx1M led to fewer whitecolored cells and an obvious decrease in the number of apoptotic cells compared to the ADR group.

ADR-mediated redox cycling caused an increase in the generation of ROS and cell damage [24]. Figure 8 revealed the effects of ROS generation in ADR-, GPx1M-, and SS-mPEG-GPx1M-treated cells. Incubation with ADR showed an obvious increase in ROS generation as indicated by the 5.90-fold increase in fluorescence intensity compared to the normal group. H9c2 cells pre-/co-administrated GPx1M (48.34 $\pm 1.62 \%$ and $55.43 \pm 3.91 \%)$ and SS-mPEG-GPx1M (44.64 \pm $1.97 \%$ and $53.54 \pm 5.39 \%$ ) followed by ADR illustrated a significant decrease in ROS production compared to H9c2 cells incubated with ADR alone $(100 \pm 3.12 \%)$. The abilities of GPx1M and SS-mPEG-GPx1M to decrease ROS accumulation in cardiomyoblasts were attributed to their ability to scavenge free radicals.

The lipid peroxidation contents were assayed by detecting MDA, which is the final product in lipid peroxidation. Compared with the control group, a significant increase in MDA was observed in the ADR group. Additionally, the MDA contents were decreased in the cells pre-/co-incubated with GPx1M (2.55 \pm 0.06

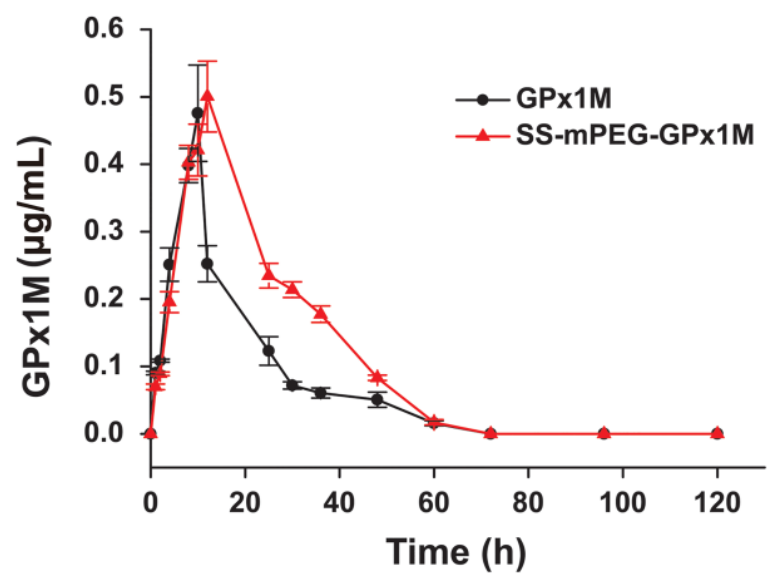

Figure 5. Blood concentration of GPx1M and SS-mPEG-GPx1M. All data were showed as mean \pm SD $(n=4)$. 
$\mathrm{nM} / \mathrm{mg}$ and $3.45 \pm 0.25 \mathrm{nM} / \mathrm{mg}$ ) and SS-mPEG-GPx1M $(2.34 \pm 0.09 \mathrm{nM} / \mathrm{mg}$ and $3.32 \pm 0.06 \mathrm{nM} / \mathrm{mg})$ compared to the ADR group (Figure 9A). These results indicated that GPx1M and SS-mPEG-GPx1M could alleviate the oxidative stress mediated by ADR in $\mathrm{H} 9 \mathrm{c} 2$ myoblasts.

The intracellular cell LDH contents in the ADR group $(538.41 \pm 4.59 \mathrm{U} / \mathrm{g})$ were obviously decreased compared with the control group $(851.73 \pm 18.60 \mathrm{U} / \mathrm{g})$. The LDH contents after preincubation with GPx1M and SS-mPEG-GPx1M were $647.76 \pm 3.92 \mathrm{U} / \mathrm{g}$ and 698.68 $\pm 9.50 \mathrm{U} / \mathrm{g}$, respectively. Furthermore, H9c2 cells coincubated with GPx1M and SS-mPEG-GPx1M resulted in an obvious increase in LDH $(612.42 \pm 2.82 \mathrm{U} / \mathrm{g}$ and $647.05 \pm 2.11 \mathrm{U} / \mathrm{g}$, respectively) compared to the ADR group (Figure 9B). The data showed that GPx1M and SS-mPEG-GPx1M could prevent cell membranes from undergoing oxidative stress damage.

\section{In vivo antioxidant effect analysis}

The cardiac enzymes analysis of LDH (Figure 10A) and CK (Figure 10B) illustrated similar results. The content of cardiac enzymes in the control group were normal. On the other hand, the levels of these enzymes in the
ADR group increased significantly. Compared with the control group, the index values of the GPx1M group and the SS-mPEG-GPx1M group were increased. The contents of LDH and CK in the GPx1M and SS-mPEGGPx1M group decreased significantly compared with that of the ADR group. The values of these substances in the SS-mPEG-GPx1M group were lower than those in the GPx1M group.

The results of MDA were shown in Figure 10C. Compared with the control group, the content of MDA in the ADR group was significantly incremental. The levels of MDA in the GPx1M and SS-mPEG-GPx1M group were the opposite of the ADR group. The content of MDA in the GPx1M group was higher than that in the SS-mPEG-GPx1M group.

The HW/BW of all groups suggested that the ADR group caused an obvious improvement of HW/BW compared with the control group (Figure 10D). Compared to the ADR group, rats of the GPx1M group and the SS-mPEG-GPx1M group exhibited significant reduced of $\mathrm{HW} / \mathrm{BW}$. Moreover, the $\mathrm{HW} / \mathrm{BW}$ of the GPx1M group was higher than that of the SS-mPEGGPx1M group.

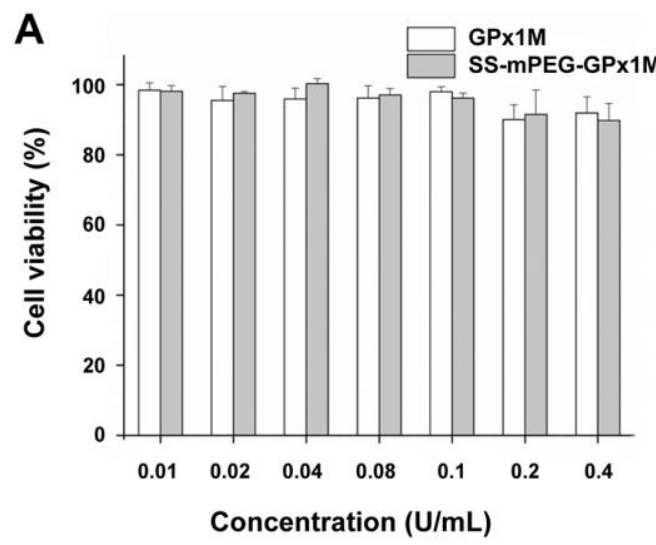

B
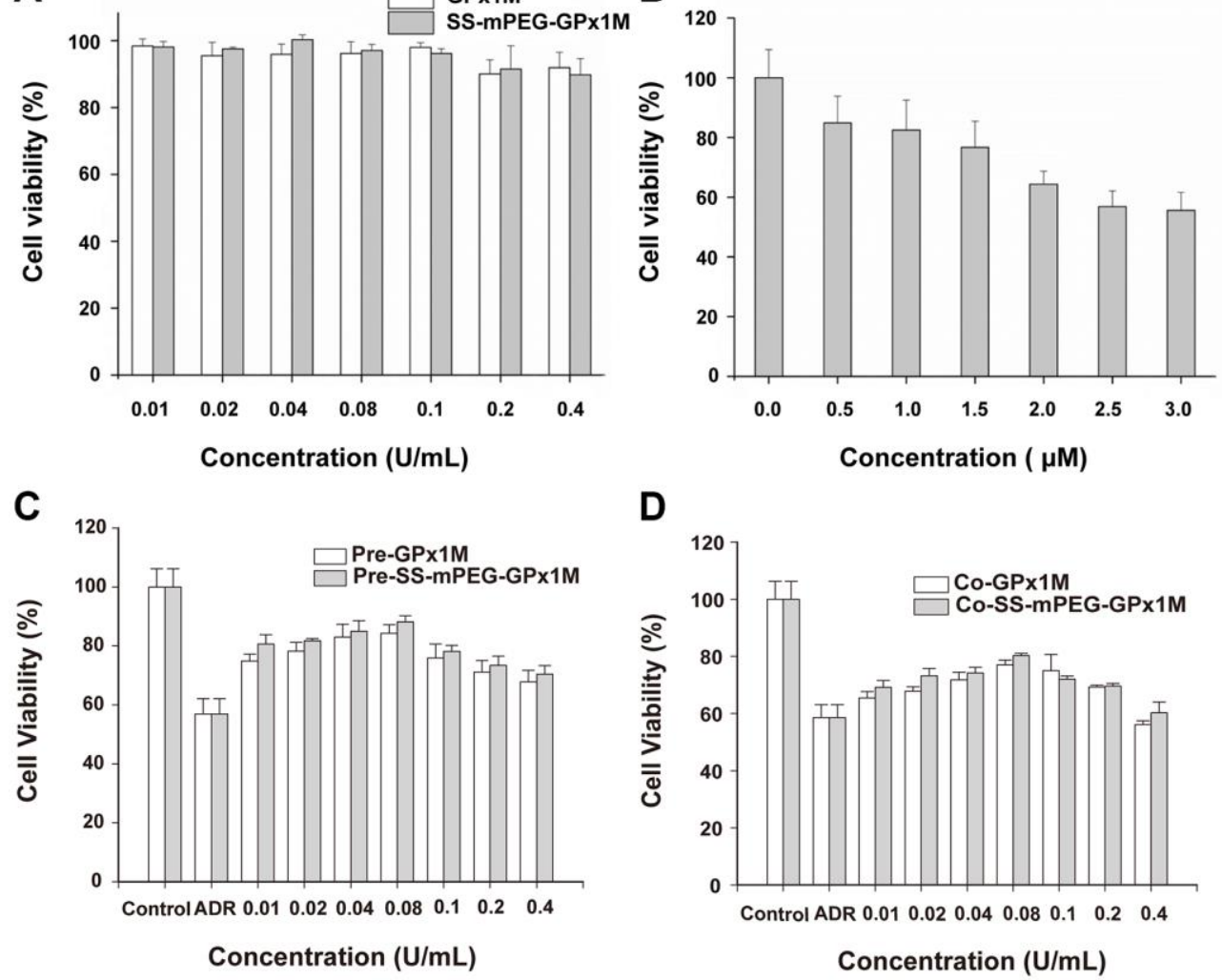

Figure 6. Determination of cell viability in vitro. Cytotoxic effects of cotreatment with GPx1M, SS-mPEG-GPx1M (A), and ADR (B) on $\mathrm{H} 9 \mathrm{c} 2$ cells. (C) Cell viabilities of H9c2 cells that were preincubated with different concentrations of GPx1M and SS-mPEG-GPx1M (0.01-0.4 $\mathrm{U} / \mathrm{mL}$ ) for $1 \mathrm{~h}$, and then treated with ADR $(2.5 \mu \mathrm{M})$ for $24 \mathrm{~h}$. (D) Cell viabilities of H9c2 cells that were treated with ADR (2.5 $\mu \mathrm{M})$ for $12 \mathrm{~h}$, and then co-incubated with different concentrations of GPx1M and SS-mPEG-GPx1M (0.01-0.4 U/mL) for another $12 \mathrm{~h}$. 
H\&E results showed that the ADR group had obvious myocardial damage, nuclear membrane disappearance, and cell deformation, while the GPx1M group and the SS-mPEG-GPx1M group had different degrees of relief compared with the ADR group, and the alleviating effect of the SS-mPEG-GPx1M group was more obvious than the GPx1M group (Figure 11A).

DHE results showed that the ADR group had obvious DHE fluorescence intensity, indicating that there was a large amount of ROS in the myocardial tissue of the ADR group compared with the control group.
Compared with the ADR group, the ROS content in the heart of the GPx1M group and the SS-mPEG-GPx1M group was significantly reduced, and the accumulation of ROS in the SS-mPEG-GPx1M group was less than that of the GPx1M group (Figure 11B-11C).

The above results indicated that GPx1M and SS-mPEGGPx1M had antioxidant effects in vivo, in which the antioxidant function of SS-mPEG-GPx1M was stronger than that of GPx1M. Moreover, the half-life of GPx1M for in vivo antioxidant therapy after PEGylation was improved. This was mainly due to the slow release, the
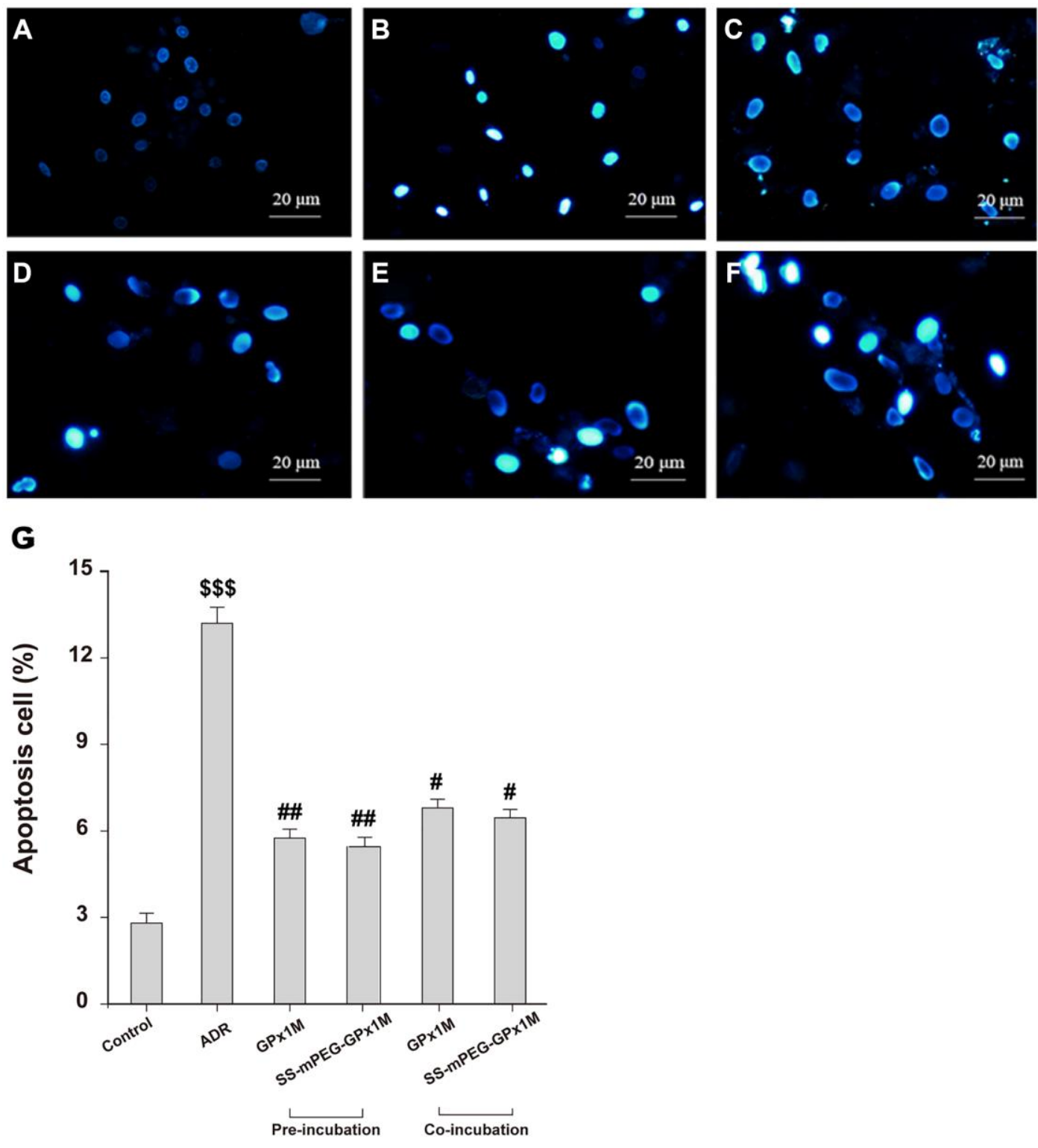

Figure 7. Effects of GPx1M and SS-mPEG-GPx1M on ADR-induced H9c2 apoptosis evaluated by Hoechst 33258 staining using a fluorescence microscope (200x). The experiments were repeated in triplicate and representative images were shown. Cells were treated with: (A) Control (DMEM). (B) $2.5 \mu \mathrm{M}$ ADR. (C) and (D) cells preincubated with GPx1M/SS-mPEG-GPx1M (0.08 U/mL) for $1 \mathrm{~h}$, respectively, and then co-incubated with $2.5 \mu \mathrm{M}$ ADR for $24 \mathrm{~h}$. (E) and (F) cells incubated with $2.5 \mu \mathrm{M}$ ADR for $12 \mathrm{~h}$, then in co-incubated with GPx1M/SS-mPEG-GPx1M $(0.08 \mathrm{U} / \mathrm{mL})$, respectively, for another $12 \mathrm{~h}$. (G) Apoptotic H9c2 cells incubated with different methods. All data were exhibited as mean \pm SD. $\$ \$ p<0.001$ vs. the control group, $\# p<0.05$ and ${ }^{\# \# p}<0.01$ vs. the ADR group. 
prolonged serum half-life, and the enhanced ability to resist protease hydrolysis of GPx1M after PEGylation which increased the cumulative amount of the drug in vivo, and ultimately enhanced the half-life of GPx1M for in vivo antioxidant therapy.

\section{DISCUSSION}

PEGylation is an efficient method to improve enzyme stability [20]. PEGylation can increase the particle size, enhance stability, and prevent effects due to temperature, $\mathrm{pH}$, and proteolytic digestion [21]. GPx1M has six lysine residues available for potential PEGylation. Based on the structure-function relationships between glutathione and GPx1M, Lys 88 and Lys 166 are near the GPx1M catalytic active center (Sec 49, Gln 84, and Trp 162), which might reduce its enzymatic activity. However, the results indicated that PEGylation of GPx1M did not decrease its enzymatic activity. There might be two reasons for this phenomenon. One reason may be due to the attachment of the PEG side chain to lysine residues remote from the catalytic center. Thus, the PEG chains will not prevent the access of binding partners or substrates to the protein's catalytic pocket [25]. Another reason may be partially attributed to the fact that glutathione is a small substrate molecule [26], which allows GPx1M to maintain its enzymatic activity. Thus, the SS-mPEG-GPx1M
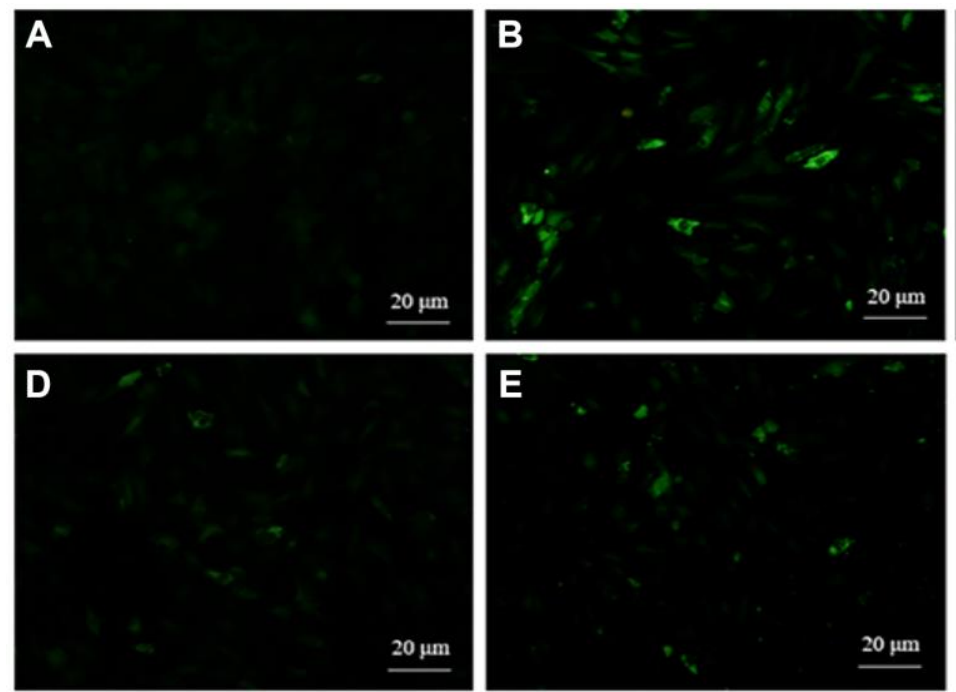

G

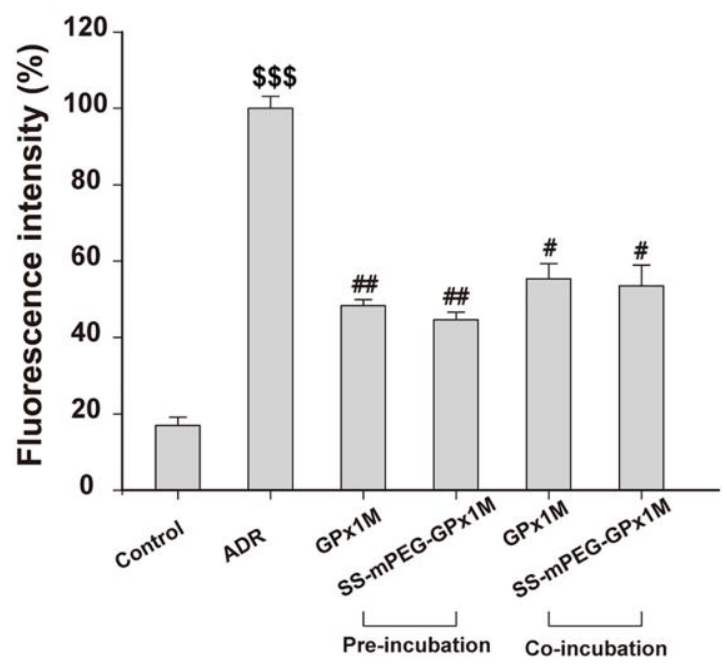

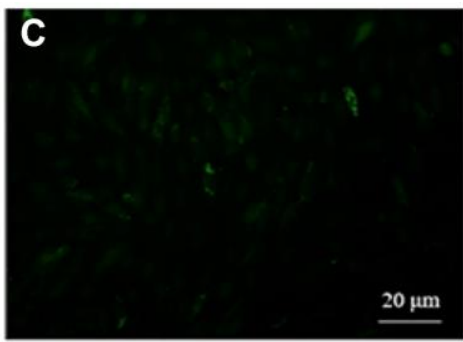

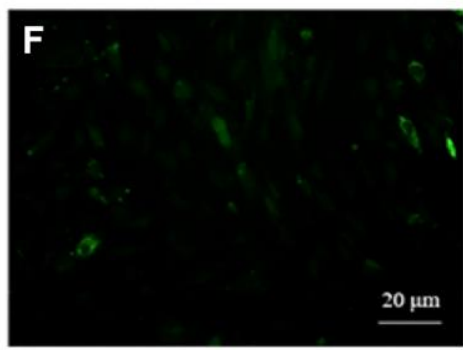



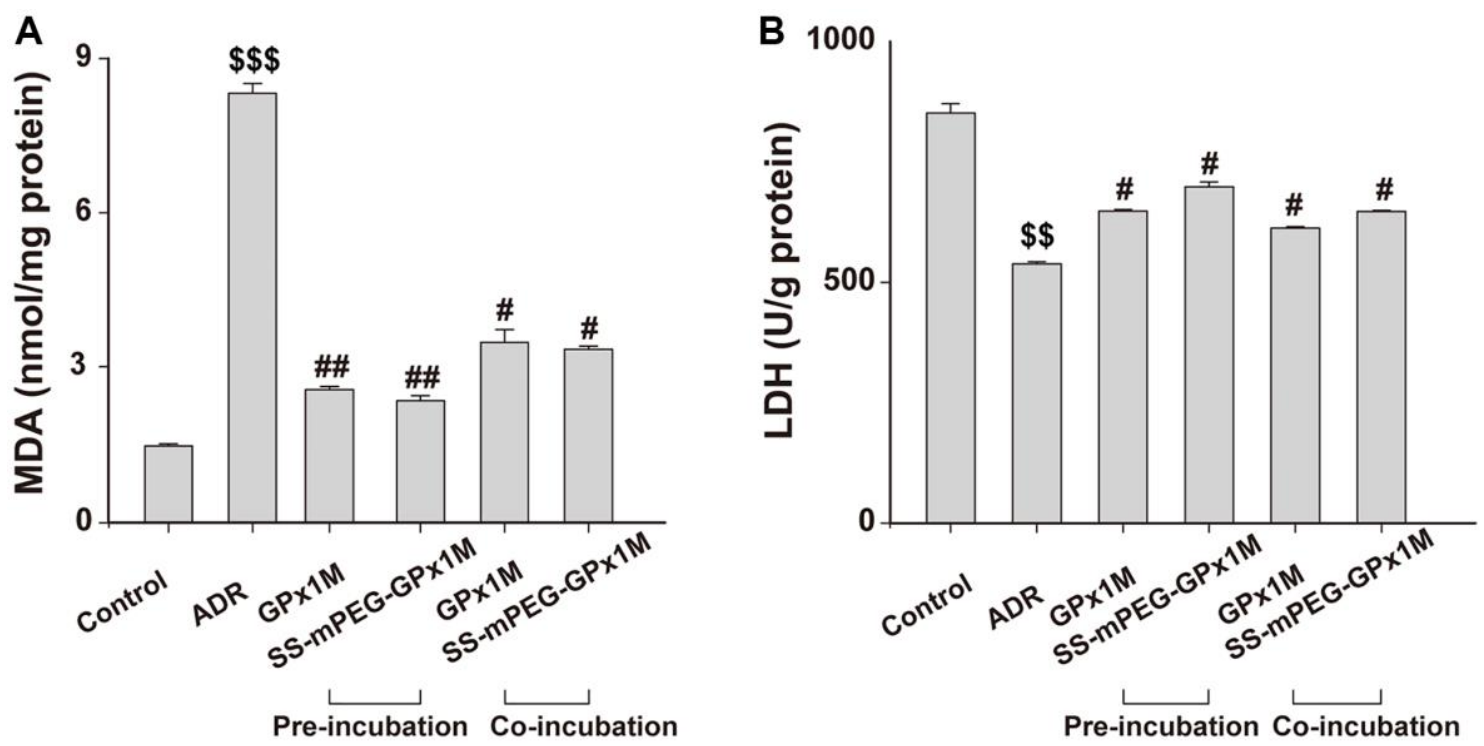

Figure 9. Effects of GPx1M and SS-mPEG-GPx1M on MDA (A) and LDH release (B) from H9c2 cells incubated with ADR. Cells were either preincubated with GPx1M/SS-mPEG-GPx1M $(0.08 \mathrm{U} / \mathrm{mL})$ for $1 \mathrm{~h}$ and then co-incubated with $2.5 \mu \mathrm{M}$ ADR for $24 \mathrm{~h}$ or incubated with $2.5 \mu \mathrm{M}$ ADR for $12 \mathrm{~h}$ and then co-incubated with GPx1M/SS-mPEG-GPx1M $(0.08 \mathrm{U} / \mathrm{mL})$ for another $12 \mathrm{~h}$. $\$ p<0.01$ and $\$ \$ p<0.001 \mathrm{vs}$. the control group, $\# p<0.05$ and ${ }^{\# \#} p<0.01$ vs. the ADR group.
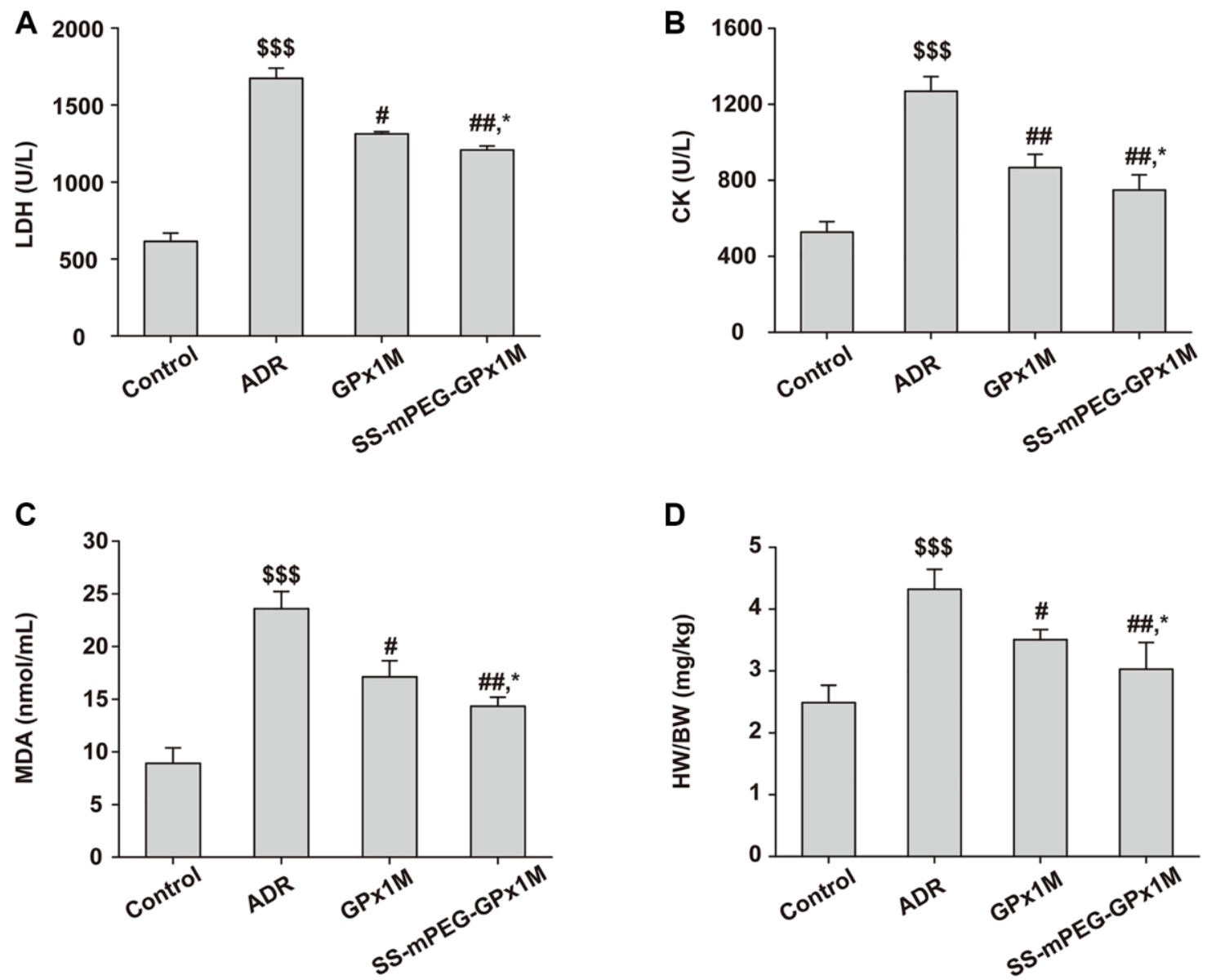

Figure 10. Antioxidant effect analysis of SS-mPEG-GPx1M in vivo. The levels of LDH (A) and CK (B) in serum were determined. The content of MDA (C) in serum and the heart weight/body weight ratios (HW/BW) (D) of all groups were analyzed. All data were exhibited as mean \pm SD $(n=5)$. ${ }^{\$ \$} p<0.001$ vs. the control group, ${ }^{\#} p<0.05$ and ${ }^{\# \#} p<0.01$ vs. the ADR group, and ${ }^{*} p<0.05$ vs. the GPx1M group. 
conjugate suggested a similar maximum enzyme activity at $37^{\circ} \mathrm{C}$ and $\mathrm{pH} 9.0$ to $\mathrm{GPx} 1 \mathrm{M}$ in the in vitro enzymatic assays. Moreover, SS-mPEG-GPx1M had a slightly increased enzyme activity with respect to thermal stability and $\mathrm{pH}$ stability. The increase in SSmPEG-GPx1M long-term stability $\left(4^{\circ} \mathrm{C}\right.$ and $\left.-20^{\circ} \mathrm{C}\right)$ might be attributed to the reduction of positive electrostatic charges, which decreased the charge exclusion within the protein [27]. Additionally, GPx1M was surrounded by PEG groups, which generated a condensed natural conformation. This alteration meant the tensile strength could not be easily stretched, leading to a decrease in the thermal vibration of enzyme molecules. In addition, PEGylation decreased the hydrophobicity of the protein surface, which made it produce more salt bridges and hydrogen bonds in the water medium and thus improved the thermal and longterm stability of GPx1M [28].
A

땀

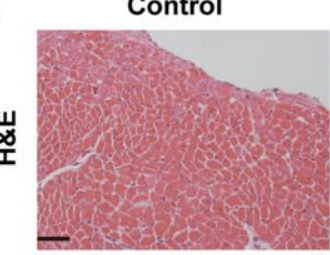

B
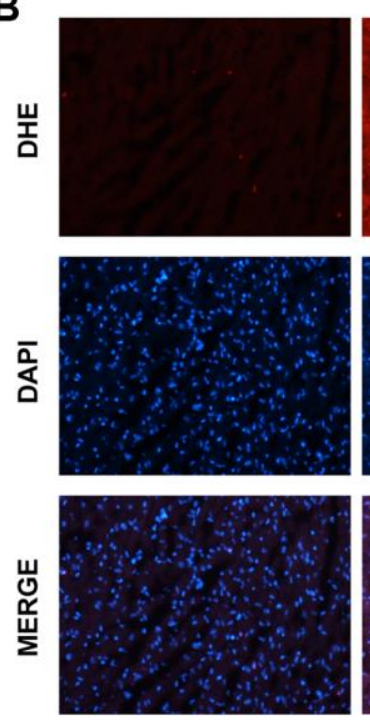

C

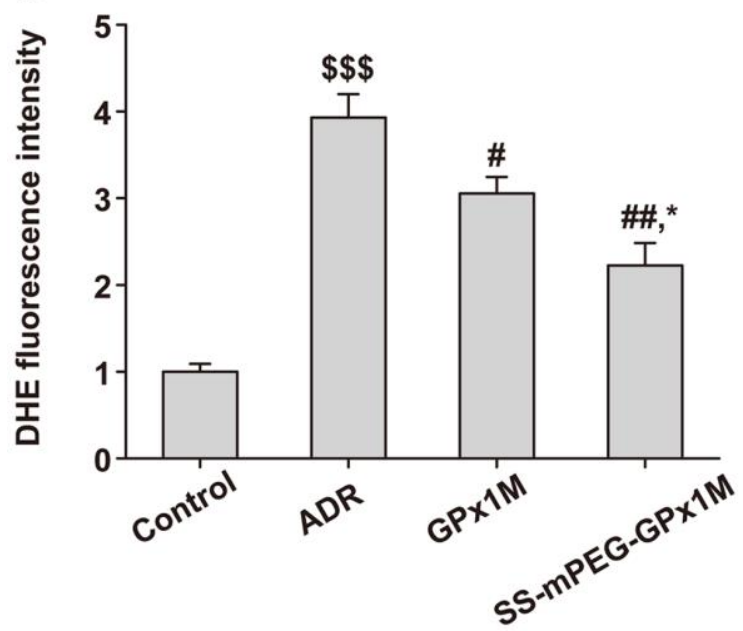

GPx1M
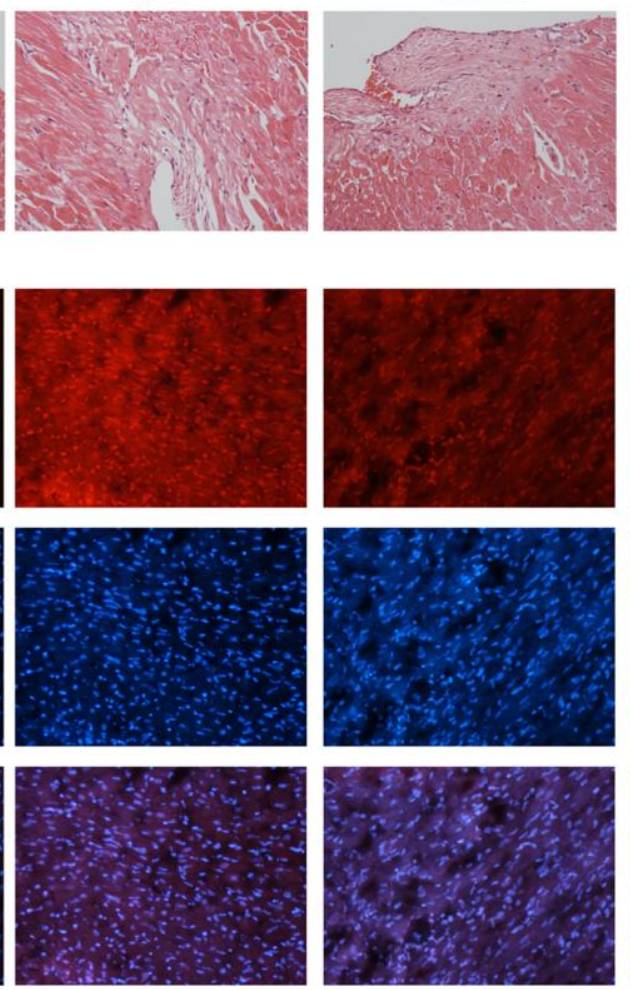

SS-mPEG-GPx1M
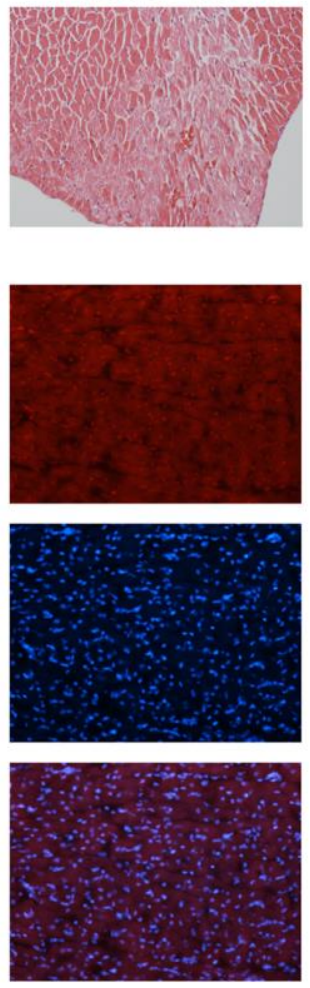

Figure 11. Histopathological changes and ROS measurement in all groups. (A) Analysis of histological evaluation in rat heart tissue using H\&E. (B) Determination the accumulation of ROS in rat heart by DHE staining. (C) DHE fluorescence intensity of each group. Scale bars, $100 \mu \mathrm{m}$. All data were exhibited as mean \pm SD. ${ }^{\$ \$} p<0.001$ vs. the control group, ${ }^{\#} p<0.05$ and ${ }^{\# \#} p<0.01$ vs. the ADR group, and ${ }^{*} p<0.05$ vs. the GPx1M group. 
ADR could acquire one electron nonenzymatically from cytochrome P450 or through enzymatically catalyzed conditions and then be converted into its semiquinone form. This semiquinone form could be oxidized to its quinone structure with a concomitant generation of superoxide free radicals [29]. ROS could directly damage mitochondria in cardiomyocytes which inducing cardiotoxicity [30]. Radicals are produced continuously in the human body as a result of serious diseases [31]. Due to the extensive use of ADR in clinical studies, researchers worldwide have attempted to decrease its severe side effects. However, the present methods (analogue drugs or combined treatment) have been proven to be mostly ineffective [32].

GPx is one of the important antioxidant enzymes (superoxide dismutase, catalase, and GPx). Natural hGPx1 exhibits significant radical scavenging activity, which might be a potential candidate for alleviating ADR-induced cardiotoxicity. GPx overexpression can decrease lipid peroxidation contents in ADR-treated human breast carcinoma cells [33], revealing that the suppression of GPx is closely related to apoptosis [34]. Thus, $\mathrm{H} 9 \mathrm{c} 2$ cells were selected as model cells to evaluate ADR-induced cardiotoxicity [35]. We observed that ADR showed a prominent and concentration-dependent toxicity in $\mathrm{H} 9 \mathrm{c} 2$ cells. However, different concentrations of GPx1M and SS-mPEG-GPx1M (0.01-0.1 U/mL) did not present any cytotoxicity. Pre-/coincubation of GPx1M and SS-mPEG-GPx1M notably decreased the cytotoxicity and increased cell viability. Moreover, SSmPEG-GPx1M exhibited similar protective effects to GPx1M on H9c2 cells.

Apoptosis results revealed that $\mathrm{H} 9 \mathrm{c} 2$ cells administered ADR presented a large number of whitecolored cells compared with the control group. Cells pre-/cotreated with GPx1M and SS-mPEG-GPx1M showed a notable decrease in white-colored cells. GPx1M could alleviate ADR-induced cytotoxicity [33]. The alleviation effects of GPx1M were also reported in other investigations, which were due to its anti-apoptotic, anti-lipid peroxidation and antioxidant effects. ADR-mediated redox cycling caused an increase in the generation of ROS and cell damage [24]. Pre-/cotreatment with GPx1M and SS-mPEGGPx1M could decrease ROS production as evident by the lower fluorescent intensity. The abilities of GPx1M and SS-mPEG-GPx1M to decrease ROS accumulation in cardiomyoblasts were attributed to their ability to scavenge free radicals.

The reduction in MDA showed that GPx1M and SSmPEG-GPx1M could alleviate the oxidative stress mediated by ADR in H9c2 myoblasts. They function by preventing lipid peroxidation and ROS generation. GPx1M and SS-mPEG-GPx1M could catalyze the attenuation of hydrogen peroxide and other lipid peroxides, while SOD could catalyze superoxide free radicals to hydrogen peroxide [36]. Based on these reasons, the MDA contents were reduced by GPx1M and SS-mPEG-GPx1M.

The presence of lipid peroxidation can lead to cardiomyoblast membrane damage, allowing intracellular components to leak into the medium. LDH is an intracellular enzyme detected following damage to cell membranes and is an important indicator of cell membrane integrity. GPx1M and SS-mPEG-GPx1M could prevent cell membranes from undergoing oxidative stress damage. GPx1M and SS-mPEGGPx1M could reduce the oxidative stress-mediated cytotoxicity, which may be due to their ability to scavenge a variety of fatty acid hydroperoxides and decrease $\mathrm{H}_{2} \mathrm{O}_{2}$ production, which in turn decreases apoptosis as well as ROS production (Figure 12).

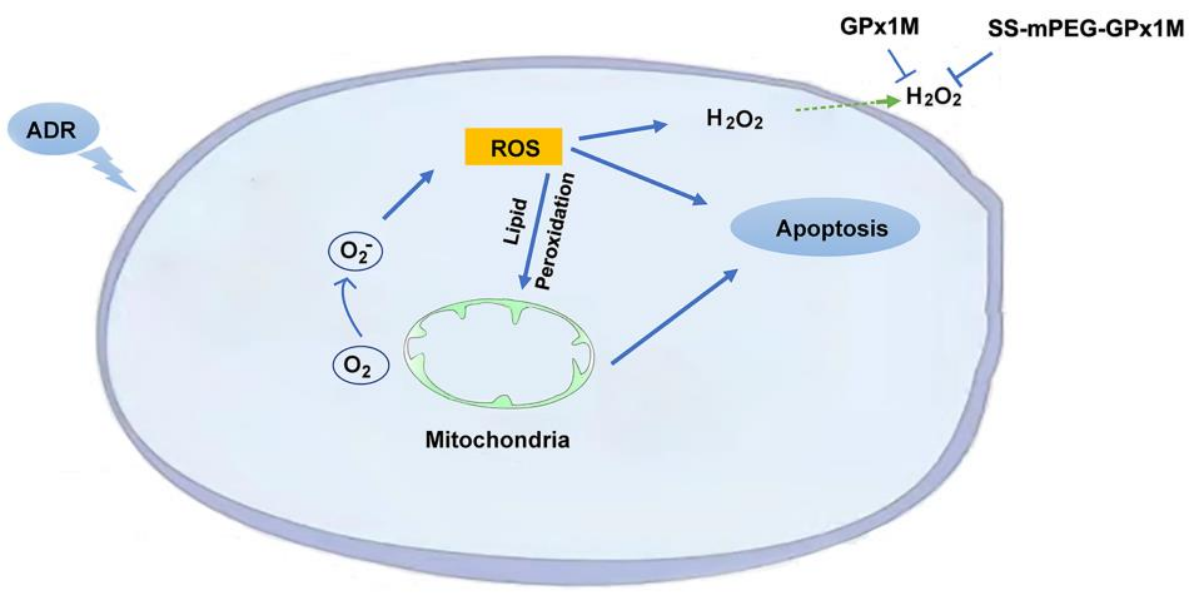

Figure 12. Schematic illustration of the mechanism of SS-mPEG-GPx1M against ADR-induced oxidative stress injury and cardiomyocyte apoptosis. 
Studies on antioxidant activity in vivo showed that the levels of cardiac enzymes ( $\mathrm{LDH}$ and CK), MDA in serum and HW/BW of the GPx1M group and the SSmPEG-GPx1M group were lower than the ADR group. Data indicated the antioxidant effect of SS-mPEGGPx1M was stronger than that of GPx1M in vivo. This may be that PEGylation could increase the molecular weight of GPx1M, so that is not easily removed by the kidney. On the other hand, PEG could cover the surface of GPx1M, and reduce the exposure of antigenic determinants. As a result, the modified GPx1M could remain in the body for a longer time which caused a prolonged biological half-life, and had more opportunities to eliminate excess reactive oxygen species.

In conclusion, the stability, the half-life and the antioxidant effect in vivo of the GPx1M was significantly improved after PEGylation while the remaining enzyme activity after modification was basically the same as GPx1M. After modification, SSmPEG-GPx1M still had an equivalent antioxidant capacity with GPx $1 \mathrm{M}$ in vitro, which did not affect the function of GPx1M. In this research, we successfully synthesized methoxypolyethylene glycol-succinimidyl succinate and prepared a novel SS-mPEG-GPx1M polymer through covalent attachment. SS-mPEGGPx1M showed improved temperature stability at 50$55^{\circ} \mathrm{C}$ and $\mathrm{pH}$ stability at $10-11$. The enzymatic activity of SS-mPEG-GPx1M at different storage temperatures, namely, $4^{\circ} \mathrm{C}$ and $-20^{\circ} \mathrm{C}$, was superior to that of GPx1M. SS-mPEG-GPx1M exhibited similar antioxidant effects to GPx1M by decreasing MDA production, inhibiting LDH release and alleviating ADR-induced $\mathrm{H} 9 \mathrm{c} 2$ cells damage. Meanwhile, SSmPEG-GPx1M had better antioxidant activity and longer blood circulation half-life than GPx1M in vivo. Thus, PEGylation could improve the stability of GPx1M and prompt the application of GPx1M as an important antioxidant and potential drug.

\section{MATERIALS AND METHODS}

\section{Materials}

Methoxy polyethylene glycols were purchased from Sigma Aldrich (USA). MTT (3-(4, 5-dimethylthiazol- 2-yl)-2, 5-diphenyl tetrazolium bromide), succinic anhydride (SA), N, N dimethyl formamide (DMF), 1-ethyl-3-[3-(dimethyl amino) propyl] carbodiimide (EDC), and N-hydroxysuccinimide (NHS) were supplied by Energy Chemical Co., Ltd. (Shanghai, China). Diethyl ether and dichloromethane were purchased from Sinopharm Chemical Reagent Co., Ltd. (Beijing, China). Fetal bovine serum (FBS), Dulbecco's modified Eagle medium (DMEM), trypsin, and phosphate buffer saline (PBS) were all supplied by Thermo Fisher Scientific Co., Ltd. (USA). LDH, creatine kinase $(\mathrm{CK})$, and MDA assay kits were provided by Nanjing Jiancheng Bioengineering Institute (Nanjing, China). Hoechst 33258 staining kit and reactive oxygen species (ROS) assay kits were supplied by Beyotime biotechnology (Jiangsu, China).

\section{Animals}

All animals were obtained from the Laboratory Animal Center of Jilin University (Changchun, China) and housed on 12-h light, 12-h dark cycle with commercial food and water. Animal experiments were carried out following the Committee for the Care and Use of Laboratory Animals of Jilin University (Changchun, China) and the Guide for the National Institutes of Health guide for the care (NIH Publication No. 8023, revised 1978).

\section{Synthesis and characterization of SS-mPEG}

SA, NHS, EDC, and mPEG were used to synthesize SSmPEG (Scheme 1). Certain amounts of SA (0.363 g), mPEG (6.002 g), and DMF (12 mL) were placed into a reaction bottle. The bottle was immersed in an oil bath and stirred at $100^{\circ} \mathrm{C}$ for $3 \mathrm{~h}$. NHS $(1.400 \mathrm{~g})$ and EDC $(2.478 \mathrm{~g})$ were added to the mixture solution at room temperature and maintained at $37^{\circ} \mathrm{C}$ for $24 \mathrm{~h}$. The obtained mixture solution was precipitated with diethyl ether $(120 \mathrm{~mL})$ at $4^{\circ} \mathrm{C}$. The raw product was dissolved in dichloromethane and precipitated with diethyl ether 4 times. SS-mPEG was dried in vacuum and the yield was $5.375 \mathrm{~g}$.

${ }^{1} \mathrm{H}-\mathrm{NMR}$ spectra of the samples were obtained with a Bruker AVIII NMR spectrometer at $25^{\circ} \mathrm{C}$ using DMSO- $d_{6}$ as the solvent and tetramethylsilane as the reference [37].

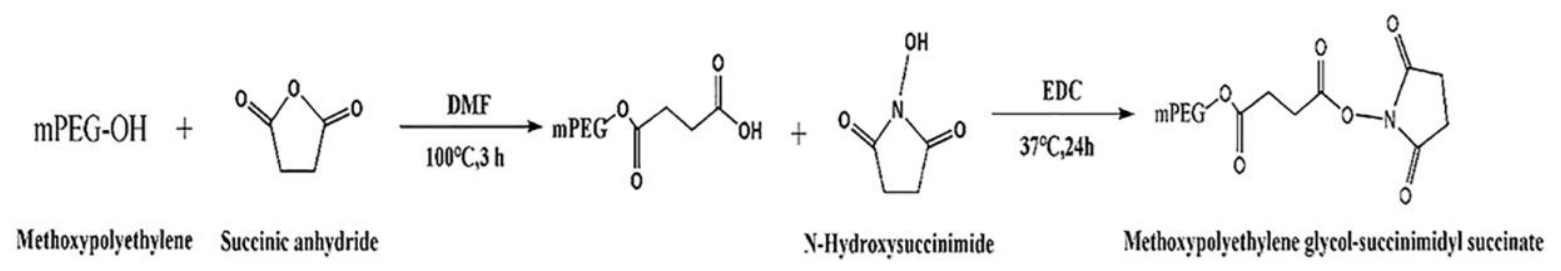

Scheme 1. Synthetic route of methoxypolyethylene glycol-succinimidyl succinate. 
Modification and purification of SS-mPEG-GPx1M

GPx1M (Seleno-hGPx1-C78/115/156S) was obtained from our previous study [4]. Conjugation of GPx1M with SS-mPEG was performed per Sakakibara et al. [38]. SS-mPEG and GPx1M were mixed with $1 \mathrm{~mL}$ of $50 \mathrm{mM}$ PBS (pH 8.5) in a tube. The mass ratio of GPx1M to SS-mPEG was 1:50. The protein solution was stirred at $80 \mathrm{rpm} / \mathrm{min}$ for $30 \mathrm{~min}$ at $4^{\circ} \mathrm{C}$. The reaction mixture was placed into a dialysis bag and dialyzed with $1 \mathrm{~L}$ of $50 \mathrm{mM}$ PBS (pH 7.4) three times over $4 \mathrm{~h}$ at $4^{\circ} \mathrm{C}$. The DEAE-sephacel was used to purify SS-mPEG-GPx1M. Buffer A was $10 \mathrm{mM}$ Tris-HCl (pH 9.0), and buffer B was $10 \mathrm{mM}$ Tris- $\mathrm{HCl}$ with $0.1 \mathrm{M}$ $\mathrm{NaCl}$. Briefly, the column materials were equilibrated with buffer A, and then loaded the sample at 0.6 $\mathrm{mL} / \mathrm{min}$. Buffer A was used again to obtain a stable baseline, then SS-mPEG-GPx1M was eluted with buffer $\mathrm{B}$ at the same flow rate.

\section{SDS-PAGE}

SDS-PAGE separations were performed using a method reported in the literature [39]. Samples were diluted with loading buffer and $20.0 \mu \mathrm{g}$ of sample was placed into each well. The gels were run at $80 \mathrm{~V}$ for $2.5 \mathrm{~h}$. The gels were stained with Coomassie Blue R-250 stain and destained with destaining solution four times.

\section{Iodine staining procedure}

The samples were diluted with loading buffer and $20.0 \mu \mathrm{g}$ of sample was placed into each well. The gels were run at $80 \mathrm{~V}$ for $2.5 \mathrm{~h}$. The gels were then immersed in $2.5 \%$ glutaraldehyde solution for fixation. First, the fixed running gel was transferred to $0.1 \mathrm{M}$ perchloric acid $(15 \mathrm{~mL})$ for $15 \mathrm{~min}$. Second, 0.1 $\mathrm{M}$ iodine solution $(2 \mathrm{~mL})$ and $5 \%$ barium chloride solution $(5 \mathrm{~mL})$ were added using the method by Manfred et al. [40]. The stained gel was transferred into a plastic box and washed with $20 \mathrm{~mL}$ of deionized water three times. The iodine-stained PEG bands appeared within a few minutes and were photographed under a camera.

\section{MALDI-TOF-MS}

Reaction mixture and purified SS-mPEG-GPx1M samples were dialyzed 5 times with $500 \mathrm{~mL}$ of deionized water each time at $4^{\circ} \mathrm{C}$. Sinapinic acid was applied as the matrix. The samples $(0.6 \mu \mathrm{L})$ were mixed with a $70 \%$ aqueous acetonitrile solution (0.6 $\mu \mathrm{L})$ and then dried at room temperature. Then, the samples were analyzed with a MALDI-TOF (Bruker Autoflex) mass spectrometer [41].

\section{Enzyme activity assay}

The enzyme activities of GPx1M and SS-mPEGGPx1M were determined according to a method in a previous study [42]. The samples and $50 \mathrm{mM}$ PBS (pH 7.4), 1 mM EDTA, 2 mM GSH, $0.2 \mathrm{mM}$ NADPH, and 1 unit GSH were incubated at $37^{\circ} \mathrm{C}$ for $5 \mathrm{~min}$. Then, $60 \mu \mathrm{M}$ hydrogen peroxide (final concentration), as the substrate, was added to start the reaction. The reaction was monitored using an ultraviolet (UV) spectrophotometer at a wavelength of $340 \mathrm{~nm}$. The enzymatic activity was expressed as $1 \mu \mathrm{M}$ of NADPH oxidized one minute.

\section{Effect of temperature, $\mathrm{pH}$, and storage time on GPx1M and SS-mPEG-GPx1M activity}

\section{Determination of GPx1M and SS-mPEG-GPXIM pH activity profiles}

Samples $(5 \mu \mathrm{L})$ of SS-mPEG-GPx1M and GPx1M were each diluted 20 -fold with $50 \mathrm{mM}$ PBS with $\mathrm{pH}$ values varying from 5.0 to 11.0 and detected for enzymatic activity as described in section "Enzyme activity assay". All values were converted to a relative value, and the highest enzyme activity was set as $100 \%$.

Determination of GPx1M and SS-mPEG-GPXIM temperature activity profiles

Temperature activity studies were applied to GPx1M and SS-mPEG-GPx1M samples in $50 \mathrm{mM}$ PBS $(40 \%$ glycerin, $\mathrm{pH}$ 7.4) as described in section "Enzyme activity assay". GPx1M and SS-mPEG-GPx1M preparations were incubated at 19, 30, 37, 45, 50 and $55^{\circ} \mathrm{C}$ for $5 \mathrm{~min}$ and assayed for their enzymatic activity as previously described. All values were converted to a relative value, and the highest enzyme activity was set as $100 \%$.

\section{Generating storage temperature stability profiles}

Storage temperature stability studies of GPx1M and SS-mPEG-GPx1M preparations were also performed. GPx1M and SS-mPEG-GPx1M samples were obtained from $50 \mathrm{mM}$ PBS buffer (40\% glycerin, $\mathrm{pH}$ 7.4). All samples were prepared at the same protein concentration before storage. GPx1M and SS-mPEGGPx1M were stored at 4 and $-20^{\circ} \mathrm{C}$. Their activities were detected over time at indicated time points. The original enzyme activity (0 day) was set as $100 \%$.

\section{Effect of trypsin on GPx1M and SS-mPEG-GPx1M activity}

The effect of PEGylation on the resistance of GPx1M to protease hydrolysis was evaluated by measuring the enzyme activity of GPx1M and SS-mPEG-GPx1M treated with trypsin for different times. GPx1M and 
SS-mPEG-GPx1M samples were digested with $10 \%$ $(\mathrm{w} / \mathrm{w})$ trypsin at $37^{\circ} \mathrm{C}$, respectively. Then, the trifluoroacetate (TFA) was used to arrest the digestion at indicated time points. The original enzyme activity (0 min) was set as $100 \%$.

\section{Determination of PEGylation site}

The LC-ESI-MS was used to analyze the PEGylation site. Briefly, after digestion using trypsin at $37^{\circ} \mathrm{C}$, peptides in GPx1M and SS-mPEG-GPx1M were extracted with solution consisting of 5\% TFA (v/v), $50 \%$ acetonitrile $(\mathrm{ACN})$, and $45 \% \mathrm{ddH}_{2} \mathrm{O}$. The RPHPLC Acclaim PepMap $C_{18}$ column $(150 \mu$ m i.d. $\times 150$ $\mathrm{mm}$ ), Ultimate 3000 system (Thermo Fisher Scientific, USA), and Q Exactive ${ }^{\mathrm{TM}}$. Hybrid Quadrupole-Orbitrap ${ }^{\mathrm{TM}}$. mass spectrometer (Thermo Fisher Scientific, USA) were used to separate, collect, and analyze all digested products of GPx1M and SS-mPEG-GPx1M. The raw MS files were analyzed and searched against target protein database based on the species of the samples using MaxQuant (1.6.2.10).

\section{Pharmacokinetics analysis of SS-mPEG-GPx1M}

All Sprague-Dawley (SD) rats were randomly divided into the GPx1M group and the SS-mPEG-GPx1M group with 4 rats in each group after housing on the animal facility for 7 days. A single intraperitoneal injection (i.p.) of GPx1M $(100 \mu \mathrm{g} / \mathrm{kg})$ were given into rats of the GPx1M group. Rats of the SS-mPEGGPx1M group received SS-mPEG-GPx1M (GPx1M equivalent) with the same way as the GPx1M group. Blood samples at different time points $(0,1,2,4,8,10$, $12,25,30,36,48,60,72,96$, and $120 \mathrm{~h}$ ) were taken from retroorbital plexus and centrifuged to obtain serum. The concentration of GPx1M or SS-mPEGGPx1M in serum was assayed by a competitive inhibition ELISA kit. The pharmacokinetic data were calculated with PKSolver 2.0 software [43-45].

\section{In vitro antioxidant effects of SS-mPEG-GPx1M}

\section{In vitro cell viability}

The in vitro cell viability was examined in $\mathrm{H} 9 \mathrm{c} 2$ cells using the MTT assay [46]. Briefly, H9c2 cells with an initial density of $1 \times 10^{5}$ viable cells/well were plated in 96-well plates and incubated for $48 \mathrm{~h}$ at $37^{\circ} \mathrm{C}$ with $5 \%$ $\mathrm{CO}_{2}$. The $\mathrm{H} 9 \mathrm{c} 2$ cells were then incubated with GPx1M/SS-mPEG-GPx1M (0.01-0.4 U/mL) and ADR $(0.5-3 \mu \mathrm{M})$, respectively. After $24 \mathrm{~h}$ of incubation, 20 $\mu \mathrm{L}$ of MTT solution $(5 \mathrm{mg} / \mathrm{mL})$ was added to each well in the plate. After $4 \mathrm{~h}$ incubation, the culture medium was extracted, $150 \mu \mathrm{L}$ of DMSO was placed in each well, and the absorbance was determined at $492 \mathrm{~nm}$ using a microplate reader (Epoch, Biotek Instruments,
USA). The cell viability was calculated by the following Equation [46]:

Cell viability $\%=\left(\mathrm{A}_{\text {sample }}-\mathrm{A}_{\text {blank }}\right) /\left(\mathrm{A}_{\text {control }}-\mathrm{A}_{\text {blank }}\right) \times 100 \%$

where $\mathrm{A}_{\text {sample }}$ represents the values obtained from the samples treated with GPx1M, SS-mPEG-GPx1M, and ADR; $A_{\text {control }}$ represents the values obtained from the cells incubated with DMEM medium and $A_{\text {blank }}$ represents the values obtained from DMEM medium.

\section{Cytotoxicity of pre- and coincubation of GPx1M/ SS-mPEG-GPXIM with ADR}

To investigate the cytotoxicity during the pre- and coincubation of GPx1M/SS-mPEG-GPx1M with ADR, $\mathrm{H} 9 \mathrm{c} 2$ cells with an initial density of $1 \times 10^{5}$ viable cells/well were plated in 96-well plates and incubated for $48 \mathrm{~h}$ at $37^{\circ} \mathrm{C}$ with $5 \% \mathrm{CO}_{2}$. The $\mathrm{H} 9 \mathrm{c} 2$ cells were preincubated with GPx1M/SS-mPEG-GPx1M (0.01$0.4 \mathrm{U} / \mathrm{mL}$ ) for $1 \mathrm{~h}$ and then incubated with an additional $2.5 \mu \mathrm{M}$ ADR (final concentration) for $24 \mathrm{~h}$ or treated with $2.5 \mu \mathrm{M}$ ADR for $12 \mathrm{~h}$ and then incubated with additional GPx1M/SS-mPEG-GPx1M (0.01-0.4 U/mL) for another $12 \mathrm{~h}$. The cell viability was determined using the MTT assay as described previously.

\section{Hoechst 33258 assay for apoptosis}

$\mathrm{H} 9 \mathrm{c} 2$ cells with an initial density of $1 \times 10^{6}$ viable cells/well were plated in 6-well plates and incubated for $48 \mathrm{~h}$ at $37^{\circ} \mathrm{C}$ with $5 \% \mathrm{CO}_{2}$. The $\mathrm{H} 9 \mathrm{c} 2$ cells were preincubated with GPx1M/SS-mPEG-GPx1M (0.08 $\mathrm{U} / \mathrm{mL}$ ) for $1 \mathrm{~h}$ and then incubated with additional ADR $(2.5 \mu \mathrm{M})$ for $24 \mathrm{~h}$ or treated with ADR $(2.5 \mu \mathrm{M})$ for $12 \mathrm{~h}$ and then incubated with additional GPx1M/ SS-mPEG-GPx1M $(0.08 \mathrm{U} / \mathrm{mL})$ for $12 \mathrm{~h}$. Following the incubation period, the cells were fixed in $1 \mathrm{~mL}$ of $0.1 \%$ formaldehyde for $20 \mathrm{~min}$ and then washed with PBS three times. Then, $1 \mathrm{~mL}$ of Hoechst 33258 staining reagent $(10 \mu \mathrm{g} / \mathrm{mL})$ was applied to stain the apoptotic cells in the dark at $37^{\circ} \mathrm{C}$ for $30 \mathrm{~min}$, followed by rinsing with PBS three times. The apoptotic cells were observed and quickly photographed under a Nikon fluorescence microscope at an excitation wavelength of 330-380 nm [47].

\section{Reactive oxygen species}

The reactive oxygen species (ROS) were detected using an ROS assay kit after $24 \mathrm{~h}$ incubation as described in section "Hoechst 33258 assay for apoptosis". Briefly, the cells were treated with the fluorescent probe 2 , 7'-dichlorofluorescin-diacetate (DCFH-DA) [48, 49]. DCFH-DA was oxidized by ROS and then converted to the fluorescent product 2', 7'-dichlorofluorescein (DCF). One milliliter of DCFH-DA reagent $(10 \mu \mathrm{M})$ was added to 6-well plates. After incubation with DCFH-DA for $30 \mathrm{~min}$ at $37^{\circ} \mathrm{C}$, the cells were rinsed with PBS three 
times. Then, the cells were quickly observed and photographed under a Nikon fluorescence microscope at an excitation wavelength of 480-535 nm. The fluorescence intensity of ROS was also detected with a Bio-Tek fluorescence microplate reader.

\section{Determination of MDA}

After a $24 \mathrm{~h}$ incubation as described in section "Hoechst 33258 assay for apoptosis", the culture medium was then discarded. The cells were rinsed with PBS three times and harvested. Then, the cells were rinsed twice more with PBS, resuspended in $100 \mu \mathrm{L}$ PBS and then ultrasonicated for $10 \mathrm{~s}$. The lipid peroxidation product MDA was detected by means of an MDA assay kit as described in the manufacturer's instructions. The MDA absorbance values were measured by ultraviolet spectroscopy at $532 \mathrm{~nm}$.

\section{Assay of $\mathbf{L D H}$}

$\mathrm{H} 9 \mathrm{c} 2$ cells were treated as described in the determination of MDA. The intracellular LDH content was evaluated using an LDH assay kit as described in the manufacturer's instructions. The LDH absorbance value was measured using a microplate reader at $450 \mathrm{~nm}$.

\section{In vivo antioxidant effects of SS-mPEG-GPx1M}

The antioxidant study of SS-mPEG-GPx1M was performed in male SD rats $(200 \pm 20 \mathrm{~g})$. After a week of adaptive feeding, all rats were randomly grouped into the control group (Control), the ADR group (ADR), the GPx1M group (GPx1M), and the SS-mPEG-GPx1M group (SS-mPEG-GPx1M). There were five rats in each group. Rats of the control group and the ADR group were treated with saline (i.p.) for 5 days, and the ADR group was given ADR $(15 \mathrm{mg} / \mathrm{kg}$, i.p.) on the 3th day. Rats of the GPx1M group received $4 \mu \mathrm{g} / \mathrm{kg} / \mathrm{d}$ GPx $1 \mathrm{M}$ (i.p.) for 5 days, and the same dose of SS-mPEGGPx1M (GPx1M equivalent) was used to the SSmPEG-GPx1M group for 5 days (i.p.). On the 3th day, ADR $(15 \mathrm{mg} / \mathrm{kg}$, i.p.) was injected into rats of the GPx1M group and the SS-mPEG-GPx1M group. Blood samples were collected from the rats anesthetized with $5 \%$ chloral hydrate at the 6th day, and centrifuged to obtain serum. The rats were sacrificed, and the heart tissues were preserved for $\mathrm{H} \& \mathrm{E}$ staining and DHE staining. The $\mathrm{LDH}, \mathrm{CK}$, and MDA of serum were measured according to the manufacturer's protocol. Heart weight/body weight ratios (HW/BW) of all rats were calculated.

\section{Statistical analysis}

All values are suggested as means \pm standard deviations (SD). The Student's $t$-test was used to analysis the differences between different groups. $p<0.05$ was considered statistically significant.

\section{Highlights}

GPx1M was modified for the first time by SS-mPEG $\left(M_{\mathrm{w}}=5 \mathrm{kDa}\right)$. SS-mPEG-GPx1M showed better stability to thermal and $\mathrm{pH}$ changes than GPx1M. GPx1M and SS-mPEG-GPx1M displayed similar antioxidant activity in vitro. SS-mPEG-GPx1M had a better antioxidant effect than GPx1M in vivo.

\section{AUTHOR CONTRIBUTIONS}

Guang-Yuan Zhang and Yan-Wei Wang conceived the study and wrote the manuscript. Jing-Yan Wei designed, supervised the experiment and wrote the manuscript. Li-Ying Guo performed conceptualization and investigation. Liang-Ru Lin conducted data curation, and formal analysis. Shao-Peng Niu participated in animal experiments. Chang-Hao Xiong performed visualization and software analysis. All authors have read and agreed to the published version of the manuscript.

\section{ACKNOWLEDGMENTS}

All authors are grateful to Prof Marie-Paule Strub and August Böck who provided us with the E. coli cysteine auxotrophic strain, BL21(DE3)-cys.

\section{CONFLICTS OF INTEREST}

The authors declare no conflicts of interest related to this study.

\section{FUNDING}

This study is supported by Department of Science and Technology of Jilin Province (20180414078GH), and Jilin Province Development and Reform Commission (2019C013) and the National Natural Science Foundation of China (Nos. 31270851 and 31872719 ).

\section{REFERENCES}

1. Brigelius-Flohé R, Maiorino M. Glutathione peroxidases. Biochim Biophys Acta. 2013; 1830:3289303.

https://doi.org/10.1016/i.bbagen.2012.11.020 PMID:23201771

2. Toribio F, Martínez-Lara E, Pascual P, López-Barea J. Methods for purification of glutathione peroxidase and related enzymes. J Chromatogr B Biomed Appl. 1996; 684:77-97. 
https://doi.org/10.1016/0378-4347(95)00504-8 PMID: 8906467

3. Wendel A. Glutathione peroxidase. Methods Enzymol. 1981; 77:325-33. https://doi.org/10.1016/S0076-6879(81)77046-0 PMID:7329310

4. Guo X, Song J, Yu Y, Wei J. Can recombinant human glutathione peroxidase 1 with high activity be efficiently produced in Escherichia coli? Antioxid Redox Signal. 2014; 20:1524-30.

https://doi.org/10.1089/ars.2013.5617 PMID:24093966

5. Davidson WB, Kennedy DG, Hughes PJ, Blanchflower WJ. The stability of glutathione peroxidase activity in plasma from cattle, pigs and sheep on storage in the presence and absence of glutathione. Vet Res Commun. 1990; 14:441-6.

https://doi.org/10.1007/BF00367055 PMID:2284706

6. Turecek PL, Bossard MJ, Schoetens F, Ivens IA. PEGylation of Biopharmaceuticals: A Review of Chemistry and Nonclinical Safety Information of Approved Drugs. J Pharm Sci. 2016; 105:460-75. https://doi.org/10.1016/i.xphs.2015.11.015 PMID:26869412

7. Abuchowski A, Kazo GM, Verhoest CR Jr, Van Es T, Kafkewitz D, Nucci ML, Viau AT, Davis FF. Cancer therapy with chemically modified enzymes. I. Antitumor properties of polyethylene glycolasparaginase conjugates. Cancer Biochem Biophys. 1984; 7:175-86. PMID: $\underline{6467175}$

8. Wang YS, Youngster S, Grace M, Bausch J, Bordens R, Wyss DF. Structural and biological characterization of pegylated recombinant interferon alpha- $2 b$ and its therapeutic implications. Adv Drug Deliv Rev. 2002; 54:547-70.

https://doi.org/10.1016/S0169-409x(02)00027-3 PMID:12052714

9. Hershfield MS, Buckley RH, Greenberg ML, Melton AL, Schiff R, Hatem C, Kurtzberg J, Markert ML, Kobayashi $\mathrm{RH}$, Kobayashi AL, Abuchowski A. Treatment of adenosine deaminase deficiency with polyethylene glycol-modified adenosine deaminase. N Engl J Med. 1987; 316:589-96.

https://doi.org/10.1056/NEJM198703053161005 PMID: $\underline{3807953}$

10. Quintanilla-Guerrero F, Duarte-Vázquez MA, Tinoco R, Gómez-Suárez M, García-Almendárez BE, VazquezDuhalt R, Regalado C. Chemical modification of turnip peroxidase with methoxypolyethylene glycol enhances activity and stability for phenol removal using the immobilized enzyme. J Agric Food Chem. 2008; 56:8058-65.

https://doi.org/10.1021/jf801400h

PMID: 18698787

11. Monfardini C, Schiavon O, Caliceti P, Morpurgo M, Veronese FM, Harris JM. A branched monomethoxypoly(ethylene glycol) for protein modification. Bioconjug Chem. 1995; 6:62-9.

https://doi.org/10.1021/bc00031a006

PMID: $\underline{7711105}$

12. Wang B, Liu S, Huang $W, M a ~ M$, Chen $X$, Zeng $W$, Liang $\mathrm{K}$, Wang $\mathrm{H}, \mathrm{Bi} Y$, Li X. Design, synthesis, and biological evaluation of hederagenin derivatives with improved aqueous solubility and tumor resistance reversal activity. Eur J Med Chem. 2021; 211:113107.

https://doi.org/10.1016/j.ejmech.2020.113107 PMID:33360797

13. Cheng S, Wang Y, Zhang Z, Lv X, Gao GF, Shao Y, Ma L, Li X. Enfuvirtide-PEG conjugate: A potent HIV fusion inhibitor with improved pharmacokinetic properties. Eur J Med Chem. 2016; 121:232-7. https://doi.org/10.1016/i.ejmech.2016.05.027 PMID:27240277

14. Benincasa M, Zahariev S, Pelillo C, Milan A, Gennaro $R$, Scocchi M. PEGylation of the peptide Bac7(1-35) reduces renal clearance while retaining antibacterial activity and bacterial cell penetration capacity. Eur J Med Chem. 2015; 95:210-9.

https://doi.org/10.1016/j.ejmech.2015.03.028 PMID:25817771

15. Harris JM, McManus SP. Introduction to nucleophilic reactivity. Nucleophilicity. 1987; 215:1-20. https://doi.org/10.1021/ba-1987-0215.ch001

16. Abuchowski A, McCoy JR, Palczuk NC, van Es T, Davis FF. Effect of covalent attachment of polyethylene glycol on immunogenicity and circulating life of bovine liver catalase. J Biol Chem. 1977; 252:3582-6. https://doi.org/10.1016/s0021-9258(17)40292-4 PMID:16907

17. Muñoz-Castañeda JR, Muntané J, Muñoz MC, Bujalance I, Montilla P, Túnez I. Estradiol and catecholestrogens protect against adriamycininduced oxidative stress in erythrocytes of ovariectomized rats. Toxicol Lett. 2006; 160:196-203. https://doi.org/10.1016/i.toxlet.2005.07.003 PMID:16112522

18. Quiles JL, Huertas JR, Battino M, Mataix J, RamírezTortosa MC. Antioxidant nutrients and adriamycin toxicity. Toxicology. 2002; 180:79-95. https://doi.org/10.1016/S0300-483X(02)00383-9 PMID:12324201 
19. Singal PK, Pierce GN. Adriamycin stimulates lowaffinity $\mathrm{Ca} 2+$ binding and lipid peroxidation but depresses myocardial function. Am J Physiol. 1986; 250:H419-25.

https://doi.org/10.1152/ajpheart.1986.250.3.H419 PMID: 3953836

20. Yaralioglu-Gurgoze S, Cetin H, Cen O, Yilmaz S, Atli MO. Changes in malondialdehyde concentrations and glutathione peroxidase activity in purebred Arabian mares with endometritis. Vet J. 2005; 170:135-7. https://doi.org/10.1016/j.tvjl.2004.04.002 PMID:15993798

21. Raddam QN, Zeidan MM, Asaad NK, Abdulrahman MA. Smoking effects on blood antioxidants level: Lactate dehydrogenase, catalase, superoxide dismutase and glutathione peroxidase in university students. J Clin Exp Pathol. 2017; 7:331-6. https://doi.org/10.4172/2161-0681.1000331

22. Thiede B, Lamer S, Mattow J, Siejak F, Dimmler C, Rudel T, Jungblut PR. Analysis of missed cleavage sites, tryptophan oxidation and N-terminal pyroglutamylation after in-gel tryptic digestion. Rapid Commun Mass Spectrom. 2000; 14:496-502. https://doi.org/10.1002/(SICl)10970231(20000331)14:6<496:AID-RCM899>3.0.CO;2-1 PMID:10717661

23. Chelulei Cheison S, Brand J, Leeb E, Kulozik U. Analysis of the effect of temperature changes combined with different alkaline $\mathrm{pH}$ on the $\beta$ lactoglobulin trypsin hydrolysis pattern using MALDITOF-MS/MS. J Agric Food Chem. 2011; 59:1572-81. https://doi.org/10.1021/jf1039876 PMID:21319805

24. Berthiaume JM, Wallace KB. Adriamycin-induced oxidative mitochondrial cardiotoxicity. Cell Biol Toxicol. 2007; 23:15-25. https://doi.org/10.1007/s10565-006-0140-y PMID:17009097

25. Liu JZ, Wang M. Improvement of activity and stability of chloroperoxidase by chemical modification. BMC Biotechnol. 2007; 7:23. https://doi.org/10.1186/1472-6750-7-23 PMID: 17511866

26. Fang X, Wang X, Li G, Zeng J, Li J, Liu J. SS-mPEG chemical modification of recombinant phospholipase $C$ for enhanced thermal stability and catalytic efficiency. Int J Biol Macromol. 2018; 111:1032-9. https://doi.org/10.1016/i.ijbiomac.2018.01.134 PMID:29366890

27. Veronese FM, Largajolli R, Boccù E, Benassi CA, Schiavon $O$. Surface modification of proteins. Activation of monomethoxy-polyethylene glycols by phenylchloroformates and modification of ribonuclease and superoxide dismutase. Appl Biochem Biotechnol. 1985; 11:141-52.

https://doi.org/10.1007/BF02798546

PMID:4026282

28. Abuchowski A, Davis FF. Preparation and properties of polyethylene glycol-trypsin adducts. Biochim Biophys Acta. 1979; 578:41-6.

https://doi.org/10.1016/0005-2795(79)90110-7 PMID: 454670

29. Goeptar AR, Te Koppele JM, Lamme EK, Piqué JM, Vermeulen NP. Cytochrome P450 2B1-mediated oneelectron reduction of adriamycin: a study with rat liver microsomes and purified enzymes. Mol Pharmacol. 1993; 44:1267-77.

https://doi.org/10.1111/j.1365-2885.1993.tb00217.x PMID:8264564

30. Bast A, Haenen GR, Bruynzeel AM, Van der Vijgh WJ. Protection by flavonoids against anthracycline cardiotoxicity: from chemistry to clinical trials. Cardiovasc Toxicol. 2007; 7:154-9. https://doi.org/10.1007/s12012-007-0018-0 PMID:17652822

31. Yeum KJ, Aldini G, Chung HY, Krinsky NI, Russell RM. The activities of antioxidant nutrients in human plasma depend on the localization of attacking radical species. J Nutr. 2003; 133:2688-91.

https://doi.org/10.1093/in/133.8.2688 PMID: 12888659

32. Khan G, Haque SE, Anwer T, Ahsan MN, Safhi MM, Alam MF. Cardioprotective effect of green tea extract on doxorubicin-induced cardiotoxicity in rats. Acta Pol Pharm. 2014; 71:861-8. https://doi.org/10.1159/000480471 PMID:25362815

33. Gouazé V, Mirault ME, Carpentier S, Salvayre R, Levade T, Andrieu-Abadie N. Glutathione peroxidase1 overexpression prevents ceramide production and partially inhibits apoptosis in doxorubicin-treated human breast carcinoma cells. Mol Pharmacol. 2001; 60:488-96.

https://doi.org/10.1089/10766290152652855 PMID: $\underline{11502879}$

34. Hockenbery DM, Oltvai ZN, Yin XM, Milliman CL, Korsmeyer SJ. Bcl-2 functions in an antioxidant pathway to prevent apoptosis. Cell. 1993; 75:241-51. https://doi.org/10.1016/0092-8674(93)80066-N PMID:7503812

35. Branco AF, Sampaio SF, Moreira AC, Holy J, Wallace KB, Baldeiras I, Oliveira PJ, Sardão VA. Differentiation-dependent doxorubicin toxicity on H9c2 cardiomyoblasts. Cardiovasc Toxicol. 2012; 
12:326-40.

https://doi.org/10.1007/s12012-012-9177-8

PMID:22744233

36. Sugden PH, Clerk A. Oxidative stress and growthregulating intracellular signaling pathways in cardiac myocytes. Antioxid Redox Signal. 2006; 8:2111-24.

https://doi.org/10.1089/ars.2006.8.2111 PMID:17034354

37. Guan $Q$, Sun D, Zhang G, Sun C, Wang M, Ji D, Yang W. Docetaxel-Loaded Self-Assembly Stearic AcidModified Bletilla striata Polysaccharide Micelles and Their Anticancer Effect: Preparation, Characterization, Cellular Uptake and In Vitro Evaluation. Molecules. 2016; 21:1641. https://doi.org/10.3390/molecules21121641 PMID:27918445

38. Sakakibara H, Tamura T, Suzuki T, Hisano T, Abe S, Murata K. Preparation and properties of alginate lyase modified with poly(ethylene glycol). J Pharm Sci. 2002; 91:1191-9. https://doi.org/10.1002/ips.10110 PMID: 11948558

39. Snider J, Neville C, Yuan LC, Bullock J. Characterization of the heterogeneity of polyethylene glycol-modified superoxide dismutase by chromatographic and electrophoretic techniques. J Chromatogr. 1992; 599:141-55.

https://doi.org/10.1016/0021-9673(92)85467-8 PMID: 1618987

40. Kurfürst MM. Detection and molecular weight determination of polyethylene glycol-modified hirudin by staining after sodium dodecyl sulfatepolyacrylamide gel electrophoresis. Anal Biochem. 1992; 200:244-8.

https://doi.org/10.1016/0003-2697(92)90460-0 PMID: 1378701

41. Suravajjala S, Cohenford M, Frost LR, Pampati PK, Dain JA. Glycation of human erythrocyte glutathione peroxidase: effect on the physical and kinetic properties. Clin Chim Acta. 2013; 421:170-6. https://doi.org/10.1016/i.cca.2013.02.032 PMID:23524033

42. Wilson SR, Zucker PA, Huang RRC, Spector A. Development of synthetic compounds with glutathione peroxidase activity. J Am Chem Soc. 1989; 111:5936-9. https://doi.org/10.1021/ja00197a065
43. Qi F, Qi J, Hu C, Shen L, Yu W, Hu T. Conjugation of staphylokinase with the arabinogalactan-PEG conjugate: Study on the immunogenicity, in vitro bioactivity and pharmacokinetics. Int J Biol Macromol. 2019; 131:896-904.

https://doi.org/10.1016/i.ijbiomac.2019.03.046

PMID:30914374

44. Zhang Y, Huo M, Zhou J, Xie S. PKSolver: An add-in program for pharmacokinetic and pharmacodynamic data analysis in Microsoft Excel. Comput Methods Programs Biomed. 2010; 99:306-14. https://doi.org/10.1016/i.cmpb.2010.01.007 PMID:20176408

45. Maso K, Grigoletto A, Raccagni L, Bellini M, Marigo I, Ingangi $V$, Suzuki $A$, Hirai $M$, Kamiya $M$, Yoshioka $H$, Pasut G. Poly(L-glutamic acid)-co-poly(ethylene glycol) block copolymers for protein conjugation. J Control Release. 2020; 324:228-37.

https://doi.org/10.1016/i.jconrel.2020.05.015 PMID:32413454

46. Guan $Q$, Zhang $G$, Sun $D$, Wang $Y$, Liu K, Wang $M$, Sun C, Zhang Z, Li B, Lv J. In vitro and in vivo evaluation of docetaxel-loaded stearic acid-modified Bletilla striata polysaccharide copolymer micelles. PLoS One. 2017; 12:e0173172.

https://doi.org/10.1371/journal.pone.0173172 PMID:28334044

47. Yang ZR, Dong WG, Lei XF, Liu M, Liu QS. Overexpression of Dickkopf-3 induces apoptosis through mitochondrial pathway in human colon cancer. World J Gastroenterol. 2012; 18:1590-601.

https://doi.org/10.3748/wjg.v18.i14.1590 PMID:22529687

48. Mehmood T, Maryam A, Zhang H, Li Y, Khan M, Ma T. Deoxyelephantopin induces apoptosis in HepG2 cells via oxidative stress, NF-KB inhibition and mitochondrial dysfunction. Biofactors. 2017; 43:63-72.

https://doi.org/10.1002/biof.1324 PMID:27628030

49. Yue $L$, Wang $W$, Wang $Y$, Du $T$, Shen $W$, Tang $H$, Wang $Y$, Yin $H$. Bletilla striata polysaccharide inhibits angiotensin II-induced ROS and inflammation via NOX4 and TLR2 pathways. Int J Biol Macromol. 2016; 89:376-88.

https://doi.org/10.1016/j.ijbiomac.2016.05.002 PMID:27151672 